NASA/TM-2004-213118
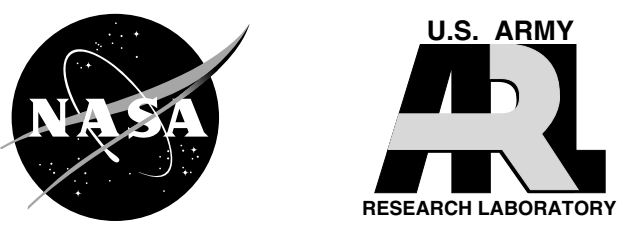

\title{
Reduced-Order Modeling and Wavelet Analysis of Turbofan Engine Structural Response Due to Foreign Object Damage (FOD) Events
}

James Turso

QSS Group, Inc., Cleveland, Ohio

Charles Lawrence

Glenn Research Center, Cleveland, Ohio

Jonathan Litt

U.S. Army Research Laboratory, Glenn Research Center, Cleveland, Ohio 
Since its founding, NASA has been dedicated to the advancement of aeronautics and space science. The NASA Scientific and Technical Information (STI) Program Office plays a key part in helping NASA maintain this important role.

The NASA STI Program Office is operated by Langley Research Center, the Lead Center for NASA's scientific and technical information. The NASA STI Program Office provides access to the NASA STI Database, the largest collection of aeronautical and space science STI in the world. The Program Office is also NASA's institutional mechanism for disseminating the results of its research and development activities. These results are published by NASA in the NASA STI Report Series, which includes the following report types:

- $\quad$ TECHNICAL PUBLICATION. Reports of completed research or a major significant phase of research that present the results of NASA programs and include extensive data or theoretical analysis. Includes compilations of significant scientific and technical data and information deemed to be of continuing reference value. NASA's counterpart of peerreviewed formal professional papers but has less stringent limitations on manuscript length and extent of graphic presentations.

- TECHNICAL MEMORANDUM. Scientific and technical findings that are preliminary or of specialized interest, e.g., quick release reports, working papers, and bibliographies that contain minimal annotation. Does not contain extensive analysis.

- CONTRACTOR REPORT. Scientific and technical findings by NASA-sponsored contractors and grantees.
- CONFERENCE PUBLICATION. Collected papers from scientific and technical conferences, symposia, seminars, or other meetings sponsored or cosponsored by NASA.

- SPECIAL PUBLICATION. Scientific, technical, or historical information from NASA programs, projects, and missions, often concerned with subjects having substantial public interest.

- TECHNICAL TRANSLATION. Englishlanguage translations of foreign scientific and technical material pertinent to NASA's mission.

Specialized services that complement the STI Program Office's diverse offerings include creating custom thesauri, building customized databases, organizing and publishing research results ... even providing videos.

For more information about the NASA STI Program Office, see the following:

- Access the NASA STI Program Home Page at http://www.sti.nasa.gov

- E-mail your question via the Internet to help@sti.nasa.gov

- Fax your question to the NASA Access Help Desk at 301-621-0134

- Telephone the NASA Access Help Desk at 301-621-0390

- Write to:

NASA Access Help Desk

NASA Center for AeroSpace Information 7121 Standard Drive

Hanover, MD 21076 
NASA/TM-2004-213118
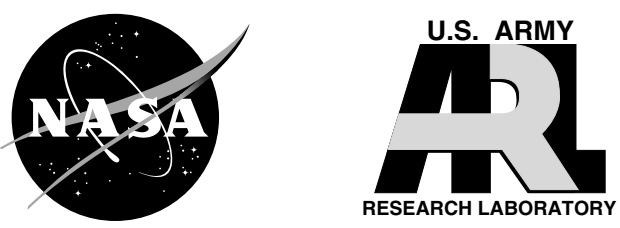

\section{Reduced-Order Modeling and Wavelet Analysis of Turbofan Engine Structural Response Due to Foreign Object Damage (FOD) Events}

James Turso

QSS Group, Inc., Cleveland, Ohio

Charles Lawrence

Glenn Research Center, Cleveland, Ohio

Jonathan Litt

U.S. Army Research Laboratory, Glenn Research Center, Cleveland, Ohio

National Aeronautics and

Space Administration

Glenn Research Center 
Trade names or manufacturers' names are used in this report for identification only. This usage does not constitute an official endorsement, either expressed or implied, by the National Aeronautics and Space Administration.

Available from

NASA Center for Aerospace Information 7121 Standard Drive

Hanover, MD 21076
National Technical Information Service 5285 Port Royal Road Springfield, VA 22100

Available electronically at http:/ /gltrs.grc.nasa.gov 


\title{
Reduced-Order Modeling and Wavelet Analysis of Turbofan Engine Structural Response due to Foreign Object Damage (FOD) Events
}

\author{
James Turso \\ QSS Group, Inc. \\ Cleveland, Ohio 44135 \\ Charles Lawrence \\ National Aeronautics and Space Administration \\ Glenn Research Center \\ Cleveland, Ohio 44135 \\ Jonathan Litt \\ U.S. Army Research Laboratory \\ Glenn Research Center \\ Cleveland, Ohio 44135
}

The development of a wavelet-based feature extraction technique specifically targeting FODevent induced vibration signal changes in gas turbine engines is described. The technique performs wavelet analysis of accelerometer signals from specified locations on the engine and is shown to be robust in the presence of significant process and sensor noise. It is envisioned that the technique will be combined with Kalman filter thermal/health parameter estimation for FOD-event detection via information fusion from these (and perhaps other) sources. Due to the lack of high-frequency FOD-event test data in the open literature, a reduced-order turbofan structural model (ROM) was synthesized from a finite element model modal analysis to support the investigation. In addition to providing test data for algorithm development, the ROM is used to determine the optimal sensor location for FOD-event detection. In the presence of significant noise, precise location of the FOD event in time was obtained using the developed wavelet-based feature.

\subsection{Introduction}

Ingestion of foreign objects by a turbofan engine, particularly birds and ice, is one of the leading causes of uncontained rotor events in commercial jet transport. There are numerous cases of bird ingestion contributing to accidents, some of them fatal [1]. Specific procedures have been developed for situations where ingestion is suspected, and forensic analysis has repeatedly shown 
that they would have been the appropriate actions to take in cases where rejected takeoffs motivated by bird ingestion resulted in accidents. These are the worst situations; in the vast majority of cases, bird ingestion does not affect the safe outcome of a flight and may, in fact, go unnoticed by the flight crew. However ingestion does pose a risk of Foreign Object Damage (FOD), and thus is important to identify, if possible. When a multi-engine aircraft flies through a flock of birds, potentially damaging more than one engine, the pilot needs to understand the status since his resulting actions may be different depending on the number of engines involved. Even in a case where there is no apparent damage to an engine as observed from the cockpit, latent effects (e.g. cracks that can be propagated by high cycle fatigue) may be present that require maintenance action [2].

The critical consequence of foreign object ingestion is engine surge, potentially resulting in the loss of power. The flight crew can recognize foreign object ingestion through a combination of instrument readings and sensory cues. These include such symptoms as a thud or bang, a fire warning, a visible flame coming out of the engine, vibration, yaw of the airplane caused by thrust imbalance, high Exhaust Gas Temperature (EGT), change in the spool speeds, smoke/odor in cabin bleed air, and Engine Pressure Ratio (EPR) change. It is important to note that for impact-type FOD (due to ice, birds, runway debris, etc.), the damage is primarily to the fan and front part of the engine, with the extent of the damage determined by the geometry, angle of impact, hardness, relative speed, etc. of the object.

One key reason for detecting FOD automatically is that most such events occur close to the ground when the flight crew is occupied flying the plane. Only after the crew stabilizes the aircraft at a safe altitude should they take action on the engine. Once the aircraft is stable, the reduced workload in the cockpit environment provides better circumstances under which the crew can analyze the situation, and they would benefit greatly by having full knowledge of the engines involved and the likelihood of the event based on data.

Given that many of the potential symptoms of FOD are not unique to that type event, an automatic system for FOD detection should take information from multiple sources to provide confidence in its diagnosis. Just like a pilot does, this system must fuse information in a way that provides a measure of the likelihood of foreign object ingestion in order to determine any corrective action. Additionally, since several of the potential symptoms are described in terms of human senses, alternate information sources need to be developed. These sources should utilize the 
standard engine sensor suite (or a very similar suite) to address issues such as certification and retrofit. Naturally processing requirements may vary from current systems simply due to the fact that additional on-line signal processing would be required, but the impact would be minimal since such a system would not be flight critical.

For approximately two decades techniques based on the Kalman filter algorithm have been applied to turbofan engine diagnostics [3,4]. Specifically, analytical (or virtual) measurements provided by Kalman filter estimators have been used for detection of engine degradation via estimation of a set of health parameters, which are generally not measurable themselves (e.g., compressor efficiency) and are calculated via knowledge of measurable quantities. The degradation monitored may be gradual in nature, e.g., worn components that increase internal clearances, resulting in decreased component efficiency. It may also be abrupt as is the case when foreign objects are ingested by the engine. Changes in component efficiencies, high and low spool speeds, and thermodynamic parameters have been determined/observed during foreign object damage (FOD) events $[3,4]$. In some cases, these parameter changes alone may not be conclusive proof that a FOD event has occurred. Absent from these investigations is the incorporation of structural vibration signals as a means to aid in positive identification of a FOD event.

To successfully apply available sensor fusion techniques, the same event should be detected using sensors that have significantly different physical characteristics (e.g., thermocouples compared to accelerometers) and rely on measuring physically different parameters (e.g., temperature and acceleration) [5,6]. It would appear that fusing health parameter estimates with structural response information acquired during a FOD event could provide conclusive evidence that a FOD event had occurred. Furthermore, fusion of virtual measurements and vibration signal features may enable discrimination between a normal aircraft maneuver/operating condition and a more severe FOD event even though both events appear to have similar looking health parameter data profiles (due to inherent limitations of the diagnostic model used). Similarly, vibration signals alone may possess FOD-like characteristics depending on the maneuver e.g., a rapid change in thrust demanded from the engine would result in transmission of temporary impulse-like force imbalances through the engine structure. The combination of traditional health parameter estimation and of state-of-the-art signal processing techniques applied to structural vibration signals (e.g, wavelet analysis $[7,8]$ ) could provide the "finger print" necessary to positively identify a FOD event. 
This paper describes the development of a wavelet-based feature (WF) extraction technique specifically targeting FOD-event induced vibration signal changes in gas turbine engines. It is envisioned that the wavelet-based feature will be fused with measurements or estimates of engine thermal parameters, themselves having FOD-specific response characteristics, to provide a highconfidence FOD event diagnosis. Successful automated identification of FOD events would be especially useful in unmanned (autonomous) vehicle applications, where the absence of the pilot precludes the use of human monitoring of engine conditions.

To the authors' knowledge, engine-specific vibration signatures associated with actual FOD events e.g., rotor frequencies excited due to foreign object impact on the fan disk, is not available in the open literature. Potential sources of high-frequency structural data, specifically high-fidelity finite element models of aircraft engines, do not easily lend themselves to sensor placement and diagnostic techniques based on well established linear system theory. As well, these models are typically computation-time intensive due to the vast amounts of time-dependant spatial data they produce and do not lend themselves for direct application to the initial stages of control and diagnostic (CDS) development and testing. To facilitate WF development, a reduced order model is synthesized to provide the structural response signals indicative of a FOD event. The low-order structural model is also used to determine the optimal accelerometer locations for feature extraction. This requires a linear model in state-space form to facilitate the calculation of an Observability Grammian matrix [9] that would determine whether a mode excited by a FOD event could be detected by a particular sensor arrangement.

\subsection{Development of reduced-order turbofan rotor structural models}

Finite element structural analysis codes provide invaluable information concerning structural deformation, stress intensities and modal behavior. However, finite element codes tend to be cumbersome and time consuming to work with when used to design and test control and diagnostic system (CDS) algorithms, especially when performing multiple design iterations. State-space models, on the other hand, are the form of choice for many signal processing and Multiple Input Multiple Output (MIMO) controller applications. A method for reduced-order modeling of turbofan rotor structures is presented which uses output from a finite-element code in the form of natural frequencies and eigenvectors to create a state-space model suitable for use in CDS 
development and testing. The resulting state-space model can easily be ported to control system development software such as the MATLAB/SIMULINK ${ }^{\circledR}$ suite of software tools [10]. The following presents the reduced-order model development process as applied to the modeling of a generic turbofan rotor, ultimately used for generating a simulated FOD event structural response.

For the purpose of developing reduced-order structural models for application to CDS development, a dynamic model based on the dominant modes of vibration of a turbofan rotorbearing system is considered adequate. The modal behavior characterized by the model should be representative of that presented in the literature for turbofan engines $[11,12]$. For the present study a specialized rotor dynamics finite element code, DyRoBes [13], is used to simulate the structural response resulting from unbalance and foreign object damage. This code is suitable for the present study since it has the capability to model critical features of an engine system and can sufficiently simulate engine dynamic response, particularly the response at sensor locations. Being a specialpurpose Finite Element code i.e., designed specifically for rotor dynamic analysis and users with a basic knowledge of FE methods, it is also relatively straightforward to use.

The structural model used for this study was derived from a generic engine model created to develop an industry standard for engine-airframe structural analysis. The model is of a dual spool rotor mounted on flexible supports (Figure 2.1). The flexible supports are characterized to simulate the static engine structure and wing.

The first spool is representative of the fan and low pressure turbine stages while the second spool represents the high pressure compressor and turbine. An interstage bearing connects the two spools together. The low pressure spool is 112 inches long and consists of 18 shaft finite elements. A large disk is located at the left end to represent the fan and several smaller disks are located on the right end for the low pressure turbine. The entire shaft weighs 2494 pounds. The high pressure spool is 80 inches long and consists of 16 shaft finite elements. There are eight disks on the shaft's left end representative of a compressor. One disk is located on the shaft's right end representative of the high pressure turbine. The high pressure shaft weighs 1280 pounds. Each shaft is supported on bearings as shown in the figure. The bearings in turn are supported on flexible supports representative of the support flexibility provides by the static engine structure. The bearing and support stiffnesses are assumed to be $1.0 \times 10^{6} \mathrm{lb} / \mathrm{in}$ and $1.0 \times 10^{3} \mathrm{Lb} / \mathrm{in}$ respectively.

The transient response from rotor imbalance and FOD of the turbofan DyRoBes model is shown in Figure 2.2. A typical rotor vibration sensor signal measured during a FOD event (with a 
sensor located at one or more of the bearing locations shown in Figure 2.1) would consist of the response of a dominant low-frequency lateral mode excited from an impulsive moment at the fan disk / rotor shaft interface (about the X-axis in Figure 2.3) due to the initial impact of the foreign object upon the fan disk. Higher frequency lateral modes would also be excited due to the high frequency content of the foreign object impact and would appear in the sensor

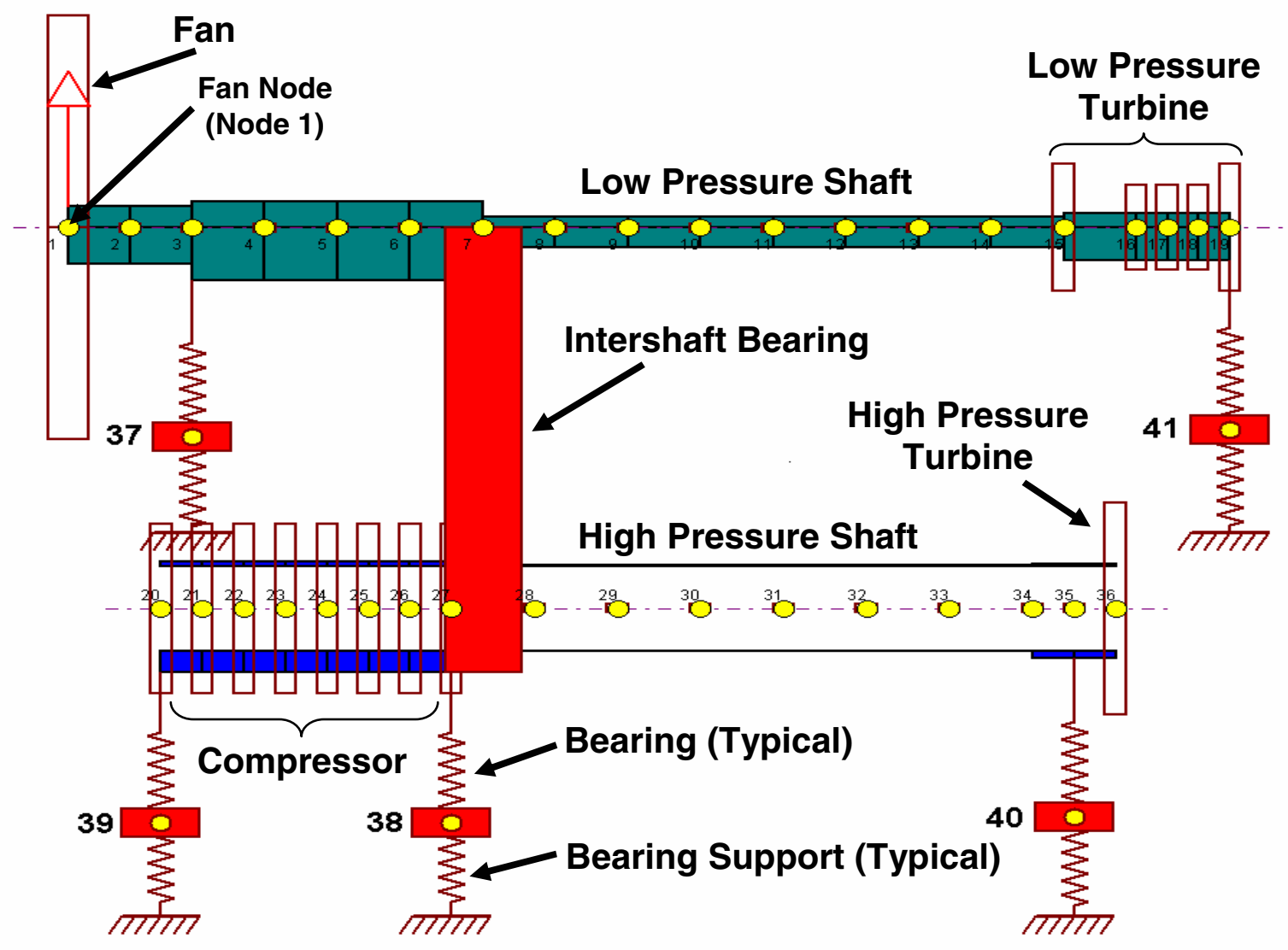

Figure 2.1. DyRoBes FEM schematic of turbofan rotor-bearing system

signal immediately after the event. Possible longer lasting effects due to resulting permanent blade damage i.e., an imbalance force occurring at a frequency corresponding to once per revolution of the rotor, may also appear. Rotating equipment tends to have a relatively small degree of inherent imbalance after manufacturing [11], which will also be included in the reduced order structural model for a "steady state" response. To the authors' knowledge, high-frequency accelerometer data from actual turbofan engine FOD events does not appear in the open literature, thus the hypothesized sequence of events are predominantly based on the authors' experience and intuition. 
The following section describes the method used to develop a Reduced Order Model (ROM) that closely approximates the actual rotor response but is more amenable to real-time assessment of feature extraction techniques used for identifying FOD.

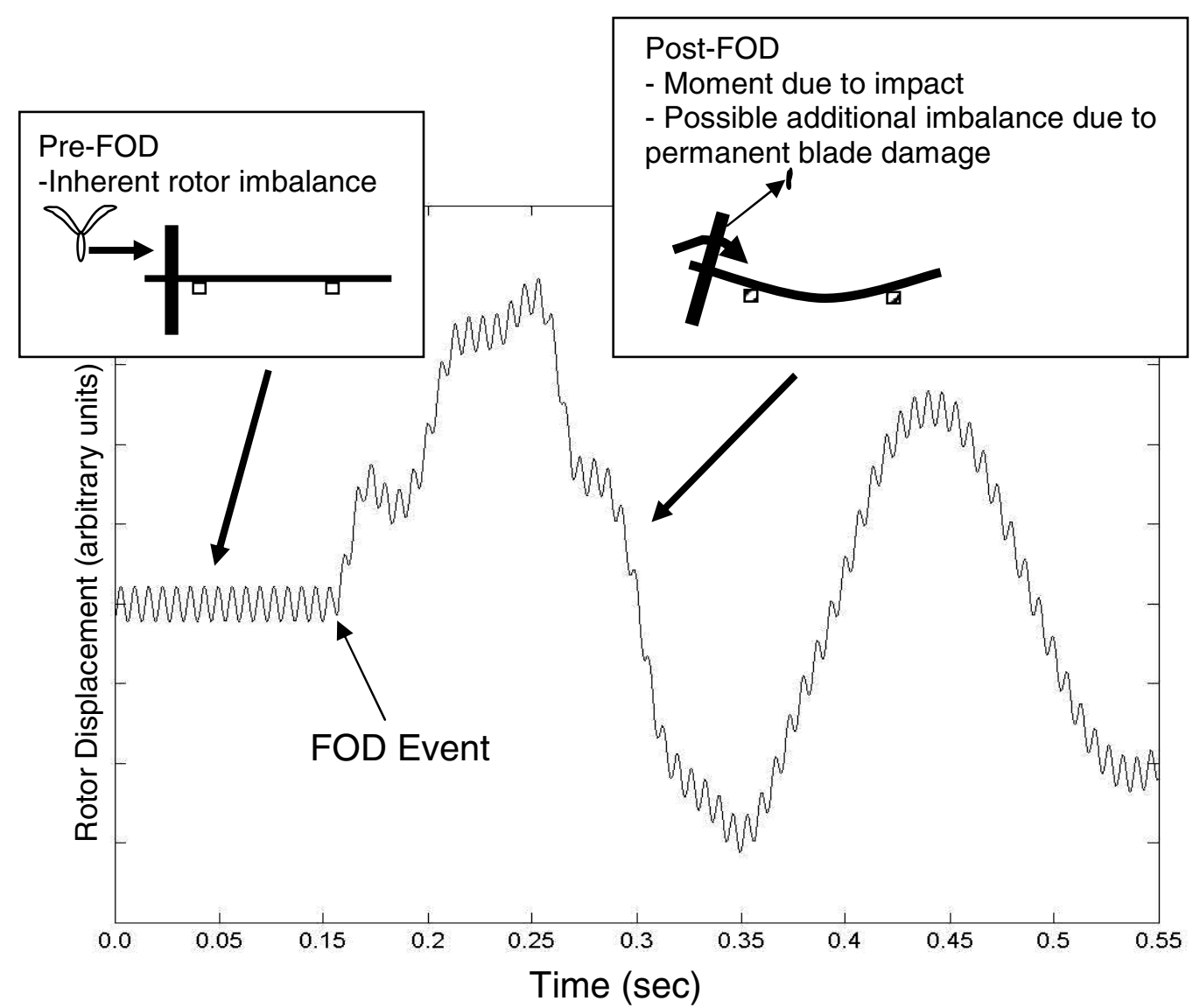

Figure 2.2. Example FOD event FEM model vibration response characteristics. Calculated displacements are functions of the imbalance magnitude and foreign object impact characteristics (e.g., relative speed, size, etc...).

\subsection{Dynamic Representation of Rotor Bearing Systems in the State Space}

Dynamic systems may be represented as transfer functions or in state-space [14]. For CDS development the state-space form is often preferred and will be the form used for the reduced order model synthesized from DyRoBes FEM modal analysis data. For a multiple degree of freedom (MDOF) translational system the equation of motion in physical coordinates is:

$$
[\mathrm{M}]\{\ddot{\mathrm{q}}\}+[\mathrm{C}]\{\dot{\mathrm{q}}\}+[\mathrm{K}]\{\mathrm{q}\}=\{\mathrm{F}\}
$$


with the damping matrix $\mathrm{C}$ typically assumed to be proportional to the mass and stiffness matrices

$$
[\mathrm{C}]=\alpha[\mathrm{M}]+\beta[\mathrm{K}]
$$

The dynamics of rotating systems are complicated by the presence of gyroscopic effects [11,15]. Expanding equation 2.1 in terms of translational and rotational degrees of freedom and including gyroscopics yields:

$$
\begin{aligned}
& {\left[\begin{array}{cccc}
\mathrm{M} & 0 & 0 & 0 \\
0 & \mathrm{M} & 0 & 0 \\
0 & 0 & \mathrm{I}_{\alpha} & 0 \\
0 & 0 & 0 & \mathrm{I}_{\theta}
\end{array}\right]\left\{\begin{array}{l}
\ddot{\mathrm{x}} \\
\ddot{\mathrm{y}} \\
\ddot{\alpha} \\
\ddot{\theta}
\end{array}\right\}+\left[\begin{array}{cccc}
\mathrm{C}_{\mathrm{xx}} & \mathrm{C}_{\mathrm{xy}} & \mathrm{C}_{\mathrm{x} \alpha} & \mathrm{C}_{\mathrm{x} \theta} \\
\mathrm{C}_{\mathrm{yx}} & \mathrm{C}_{\mathrm{yy}} & \mathrm{C}_{\mathrm{y} \alpha} & \mathrm{C}_{\mathrm{y} \theta} \\
\mathrm{C}_{\alpha \mathrm{x}} & \mathrm{C}_{\alpha \mathrm{y}} & \mathrm{C}_{\alpha \alpha} & \mathrm{C}_{\alpha \theta}-2 \mathrm{I}_{\alpha} \Omega \\
\mathrm{C}_{\theta \mathrm{x}} & \mathrm{C}_{\theta \mathrm{y}} & \mathrm{C}_{\theta \alpha}+2 \mathrm{I}_{\theta} \Omega & \mathrm{C}_{\theta \theta}
\end{array}\right]\left\{\begin{array}{l}
\dot{\mathrm{x}} \\
\dot{\mathrm{y}} \\
\dot{\alpha} \\
\dot{\theta}
\end{array}\right\}+} \\
& {\left[\begin{array}{lllll}
\mathrm{K}_{\mathrm{xx}} & \mathrm{K}_{\mathrm{xy}} & \mathrm{K}_{\mathrm{x} \alpha} & \mathrm{K}_{\mathrm{x} \theta} \\
\mathrm{K}_{\mathrm{yx}} & \mathrm{K}_{\mathrm{yy}} & \mathrm{K}_{\mathrm{y} \alpha} & \mathrm{K}_{\mathrm{y} \theta} \\
\mathrm{K}_{\alpha \mathrm{x}} & \mathrm{K}_{\alpha \mathrm{y}} & \mathrm{K}_{\alpha \alpha} & \mathrm{K}_{\alpha \theta} \\
\mathrm{K}_{\theta \mathrm{x}} & \mathrm{K}_{\theta \mathrm{y}} & \mathrm{K}_{\theta \alpha} & \mathrm{K}_{\theta \theta}
\end{array}\right]\left\{\begin{array}{l}
\mathrm{x} \\
\mathrm{y} \\
\alpha \\
\theta
\end{array}\right\}=\left\{\begin{array}{l}
\mathrm{F}_{\mathrm{x}} \\
\mathrm{F}_{\mathrm{y}} \\
\mathrm{F}_{\alpha} \\
\mathrm{F}_{\theta}
\end{array}\right\}}
\end{aligned}
$$

Unlike a non-rotating system, the damping coefficient matrix in Equation 2.3 is a function of the shaft rotational speed, $\Omega$ i.e., gyroscopic effects result in the rotor's lateral natural frequencies and mode shapes being a function $\Omega$. To determine the natural frequencies and mode shapes, assume that the free response of the system is sinusoidal in nature i.e.,

$$
\{q(t)\}=\{\varphi\} e^{i \omega} n^{t}
$$

where $\{\varphi\}$ is the mode shape (eigenvector) corresponding to $\omega_{n}$, the natural frequency (eigenvalue). $\mathrm{N}$ is the number of modes included in the model. Inserting Equation 2.4 into the unforced, undamped version of Equation 2.3 gives

$$
\left(-\omega_{\mathrm{n}}{ }^{2}[\mathrm{M}]+i \omega_{\mathrm{n}}[\mathrm{G}]+[\mathrm{K}]\right)\{\varphi\}=0
$$


where the gyroscopic matrix $\mathrm{G}$ is given by

$$
\left[\begin{array}{cccc}
0 & 0 & 0 & 0 \\
0 & 0 & 0 & 0 \\
0 & 0 & 0 & -2 \mathrm{I}_{\alpha} \Omega \\
0 & 0 & 2 \mathrm{I}_{\theta} \Omega & 0
\end{array}\right]
$$

A trivial solution to Equation 2.5 is obtained with $\{\varphi\}=0$. For a nontrivial solution

$$
\left(-\omega_{\mathrm{n}}^{2}[\mathrm{M}]+i \omega_{\mathrm{n}}[\mathrm{G}]+[\mathrm{K}]\right)=0
$$

must be satisfied. To obtain a reduced order linear model with coefficients that are independent of $\Omega$, i.e., with constant natural frequencies $\omega_{\text {ni }}(i=1 . . N)$ and modal damping, it is assumed that the natural frequencies and modes shapes calculated via Equation 2.7 at the rotor critical speeds adequately account for the effects of gyroscopics over the operating range of interest. For the rotor described in Section 2.0, the $\omega_{\mathrm{ni}}$ and $\varphi_{\mathrm{i}}$ are calculated using the DyRoBes FEM code. The mode shapes $\varphi_{\mathrm{i}}$ obtained are orthogonal with respect to the mass and stiffness matrices and provide the following normalization

$$
\begin{aligned}
& \left\{\varphi_{i}\right\}^{T}[M]\left\{\varphi_{i}\right\}=1 \\
& \left\{\varphi_{i}\right\}^{T}[K]\left\{\varphi_{i}\right\}=\omega_{\text {ni }}^{2}
\end{aligned}
$$

Given the assumptions described above, the equations of motion for the linearized rotational system take the form of Equation 2.1. For lightly damped systems the matrix C is typically assumed to be diagonal [16]. With the eigenvectors mass-normalized and $[\Phi]=\left[\varphi_{1} \cdots \varphi_{\mathrm{N}}\right]$, the coordinate transformation

$$
\{\mathrm{q}(\mathrm{t})\}=[\Phi]\{\eta(\mathrm{t})\}
$$


is inserted into Equation 2.1 and pre-multiplied by $\Phi^{\mathrm{T}}$. The dynamics of the system in modal coordinates are

$$
\{\ddot{\eta}\}+\operatorname{diag}\left[2 \xi_{\mathrm{i}} \omega_{\text {ni }}\right]\{\dot{\eta}\}+\operatorname{diag}\left[\omega_{\text {ni }}^{2}\right]\{\eta\}=\Phi^{\mathrm{T}}\{\mathrm{F}\}
$$

with the corresponding state-space form

$$
\begin{aligned}
& \left.\left\{\begin{array}{l}
\dot{\eta} \\
\ddot{\eta}
\end{array}\right\}=\left[\begin{array}{c}
0 \\
-\operatorname{diag}\left[\omega_{\text {ni }}^{2}\right]
\end{array}\right]-\operatorname{diag}\left[\begin{array}{c}
\mathrm{I} \\
2 \xi_{\mathrm{i}} \omega_{\text {ni }}
\end{array}\right]\right]\left\{\begin{array}{l}
\eta \\
\dot{\eta}
\end{array}\right\}+\Phi^{\mathrm{T}}\left\{\begin{array}{l}
0 \\
F
\end{array}\right\} \\
& \{\mathrm{q}\}=\left[\begin{array}{ll}
\Phi & 0
\end{array}\right]\left\{\begin{array}{l}
\eta \\
\dot{\eta}
\end{array}\right\}
\end{aligned}
$$

and the modal damping ratios $\xi_{\mathrm{i}}$ defined as [16]

$$
\xi_{\mathrm{i}}=\frac{C_{i}}{C_{\text {icritical }}}
$$

For the present study, the coordinates of interest (Figure 2.3) are

$$
\{\mathrm{q}\}=\left\{\begin{array}{l}
\mathrm{y} \\
\theta
\end{array}\right\}
$$

at specified points (i.e., node locations in Figure 2.1) in the rotor-bearing system.

The above presents a simplified formulation for the equations of motion of a rotational system which, in a linearized sense, include the gyroscopic effects. These effects are accounted for in DyRoBes' analyses. Modal damping ratio estimates are based on whirl analysis log-decrement calculations at the rotor-bearing system critical speeds and the nominal speed of rotation. Comparison of the reduced-order structural model frequency response (to an assumed imbalance) and transient response to the FEM-generated data will provide a measure of the fidelity of the reduced-order model to appropriately describe a FOD-event induced structural response. 

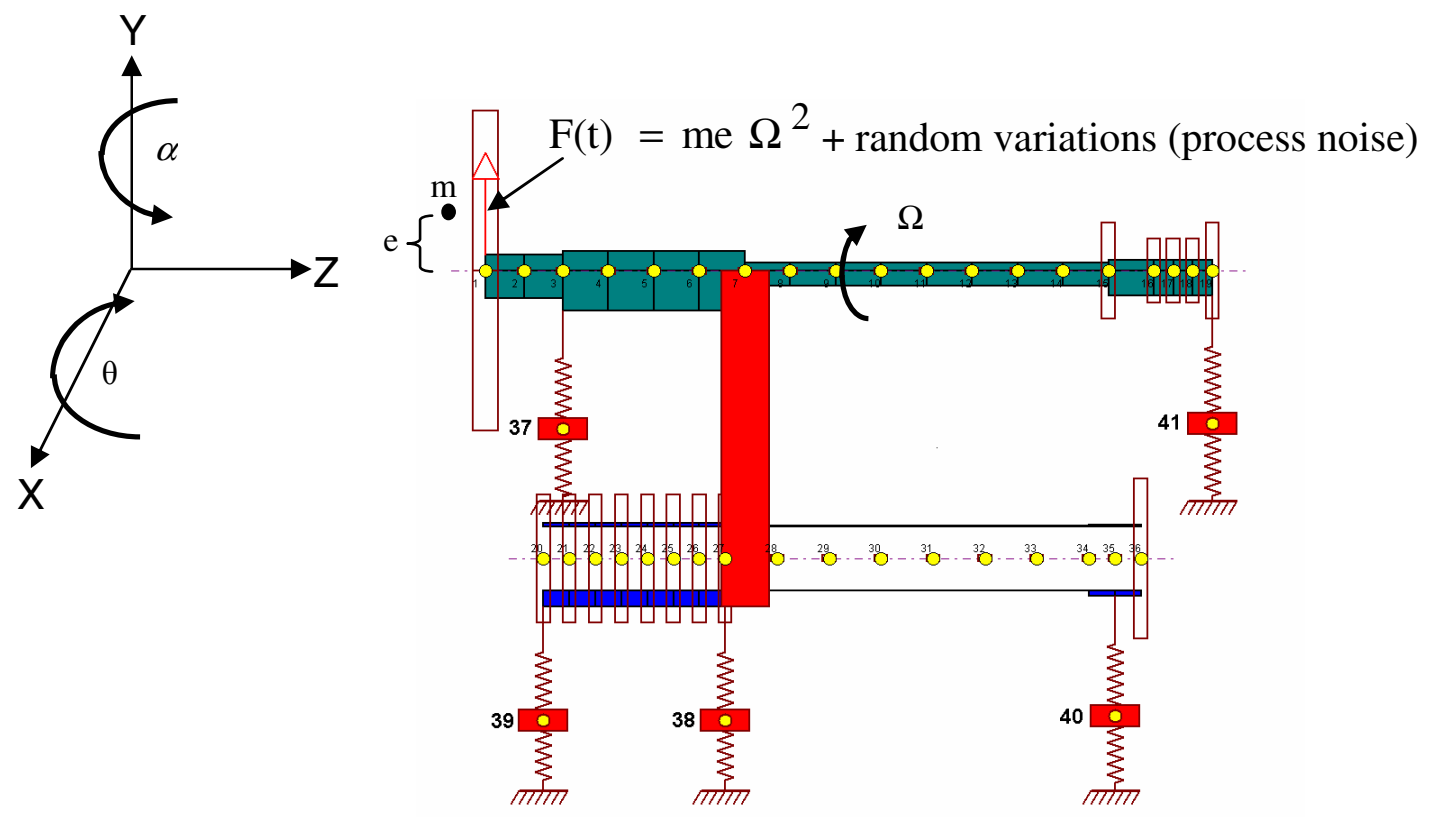

Figure 2.3. Coordinate system used in the FEM and reduced order state space structural models. Cyclic imbalance forces are perpendicular to the Z-axis. Impulse moments due to a FOD event are about the $\mathrm{X}$-axis.

\subsection{Foreign Object Damage Events modeled using Reduced Order Rotor Models from FEM output data.}

The state space model presented in Equation 2.12 requires the modal or natural frequencies of the system and the eigenvectors (i.e., modal displacements) at specified locations on the rotor or bearings / supports. For the purposes of FOD detection algorithm development, the locations of interest would be those corresponding to possible vibration sensor locations i.e., nodes corresponding to the bearings and supports as shown in Figure 2.1. Commercial FEM codes can readily provide this information [13]. Transformation from modal coordinates to physical coordinates is performed via Equation 2.10, with the matrix $\Phi$ formed by columns corresponding to the eigenvectors for each frequency being considered. To transform external forces on selected locations on the shaft (or supports) from physical to modal coordinates, the external force vector is pre-multiplied by $\Phi^{\mathrm{T}}$.

Physical (continuous) systems are inherently infinite order. Thus FEM, being lower order than the physical system being modeled, are implicitly inaccurate with FEM being more accurate in the low frequency range. The frequencies of interest are from 0 to $20,000 \mathrm{rpm}$, with the nominal rotational speed of the low pressure shaft being $9000 \mathrm{rpm}$. This frequency range will provide the 
required response due to fan imbalance, as well as the impulse response characteristics due to FOD impact upon the fan disk. For adequate imbalance response over the full range of operating speeds, the natural frequencies and mode shapes obtained from the FEM correspond to the so-called critical speeds of the shaft [11]. To attain proper response to a FOD event, several of the lateral modes calculated via an FEM whirl analysis at a specified rotor speed are included in the model as well. The number of lateral modes included is determined by the performance of the ROM with respect to the FEM. Once again, the goal of the present study is to develop structural models to test realtime diagnostic algorithms, with these models providing acceptable response characteristics for the forcing functions of interest (imbalance and foreign object impact) while maintaining the model order low. The reduced-order model development technique described above can be applied to FEM developed using codes intended for more elaborate analyses.

The reduced order dynamic model was implemented in MATLAB $®$, using the companion software package SIMULINK®, in state-space form. Figure 2.4 depicts the SIMULINK® structural model. Gas turbine rotors tend to have an inherently small degree of imbalance, which is modeled as an input corresponding to a variable amplitude sine wave with a frequency equal to the high and / or low speed rotor speeds. Imbalance force amplitude is frequency dependent according to the following relation

$$
\mathrm{F}_{\text {imbalance }}=\mathrm{me} \Omega^{2}
$$

where $\mathrm{m}$ is the total mass of the rotating component, e is the effective eccentricity in inches, and $\Omega$ is the shaft rotational speed in $\mathrm{rad}_{-} \mathrm{s}^{-1}$. If a FOD event results in additional imbalance, the eccentricity is increased by an additional amount. For the present study, the fan is assumed to have an eccentricity (i.e., inherent imbalance) of 0.001 inch.

A FOD event is modeled as an object hitting a point along the radius of the fan, resulting in a moment input at the node on the rotor corresponding to the fan location (Node 1 in Figure 2.1). The magnitude of the input moment is determined as follows. Given a foreign object of mass $\mathrm{m}_{\mathrm{FO}}$ with an initial linear velocity relative to the fan disk $\mathrm{v}_{\mathrm{FO}}$ along the z-axis (Figure 2.3), conservation of angular momentum may be applied to determine an estimate of the initial angular velocity $\dot{\theta}$ of the 


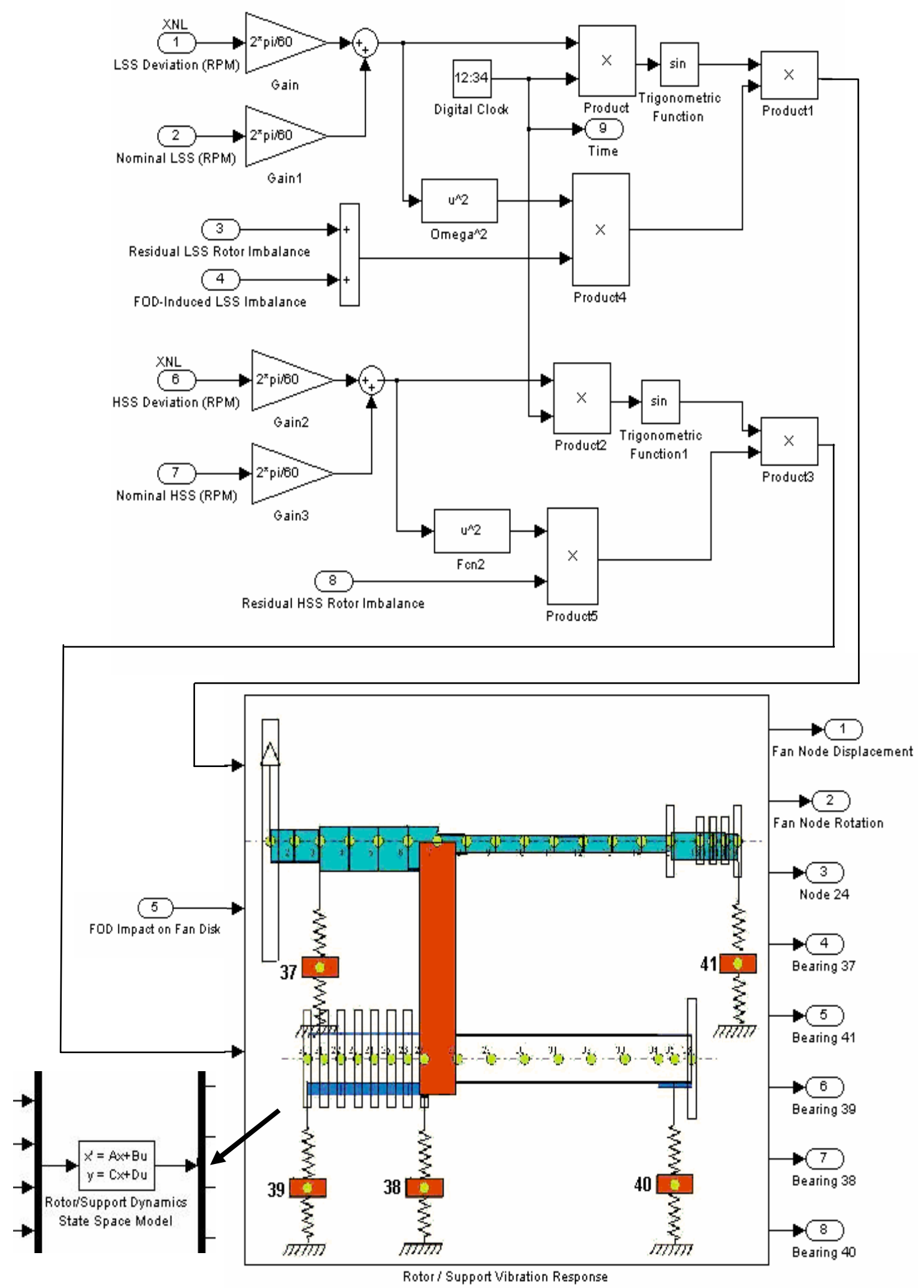

Figure 2.4. MATLAB/SIMULINK implementation of the reduced order turbofan rotor/bearing system structural model. 
fan disk about an axis perpendicular to the axis of rotation of the rotor (X-axis in Figure 2.3) due to the impact i.e.,

$$
\dot{\theta}=\frac{\mathrm{rm}_{\mathrm{FO}} \mathrm{v}_{\mathrm{FO}}}{\mathrm{I}_{\theta}}
$$

where $I_{\theta}$ is the moment of inertia of the fan disk about the $X$ axis (Figure 2.3) and $r$ is the distance of the impact from the axis of rotation ( $\mathrm{Z}$ axis in Figure 2.3). The corresponding moment applied to the rotor at node 1 from the impulse load on the fan disk is determined by the rate of change of angular momentum, given a specified time interval for the impact to occur $\Delta \mathrm{t}$.

$$
\mathrm{F}_{\theta}=\mathrm{I}_{\theta} \frac{\Delta \dot{\theta}}{\Delta \mathrm{t}}
$$

The above treatment provides a straight-forward means for determining the impulse-load related torque input to the rotor during the initial stages of the FOD event, and is considered to be adequate within the level of complexity of the model needed for real-time diagnostic system development. As mentioned previously, information regarding specific FOD events does not appear in the open literature. The FOD event impact time interval, $\Delta \mathrm{t}$, is dependant upon random factors such as foreign object geometry, location and angle of impact, foreign object hardness, relative speed, etc. and is estimated based on the authors" "intuitive feel" for an event that would cause damage.

Figure 2.5 presents a frequency response comparison of 4,10 , and 25 degree of freedom (DOF) reduced order models with the frequency response of the 154 DOF DyRoBes FEM (refer to Figure 2.1 for node locations). Figures 2.6 and 2.7 present the displacement response of the 10 DOF ROM and FEM to a combined FOD event - imbalance input. Figure 2.6 presents the response at bearing / support location 37 to a "large" FOD event $\left(\mathrm{m}_{\mathrm{FO}}=2 \mathrm{lbm}\right)$ and a "small" FOD event $\left(\mathrm{m}_{\mathrm{FO}}=0.25 \mathrm{lbm}\right)$. Figure 2.7 presents the response at bearing / support location 39 to a "large" FOD event $\left(\mathrm{m}_{\mathrm{FO}}=2 \mathrm{lbm}\right)$ and a "small" FOD event $\left(\mathrm{m}_{\mathrm{FO}}=0.25 \mathrm{lbm}\right)$. The imbalance input is calculated using Equation 2.15 with an eccentricity of 0.001 inches concentrated at the fan node (node 1 in Figure 2.1). The magnitude of the FOD event moment input at node 1 is calculated using 
Equation 2.16 with a radius of 20 inches, specified mass, a $\Delta t$ of 0.1 seconds, and a relative velocity of $300 \mathrm{mph}$. To provide adequate FOD event response characteristics, the first lateral mode from an FEM whirl analysis at $9000 \mathrm{rpm}$ was included. The 10 DOF model provides acceptable correspondence to the FEM and is considered sufficient for the present study.

Differences between the reduced order model and the FEM are due to the assumptions made, i.e.,
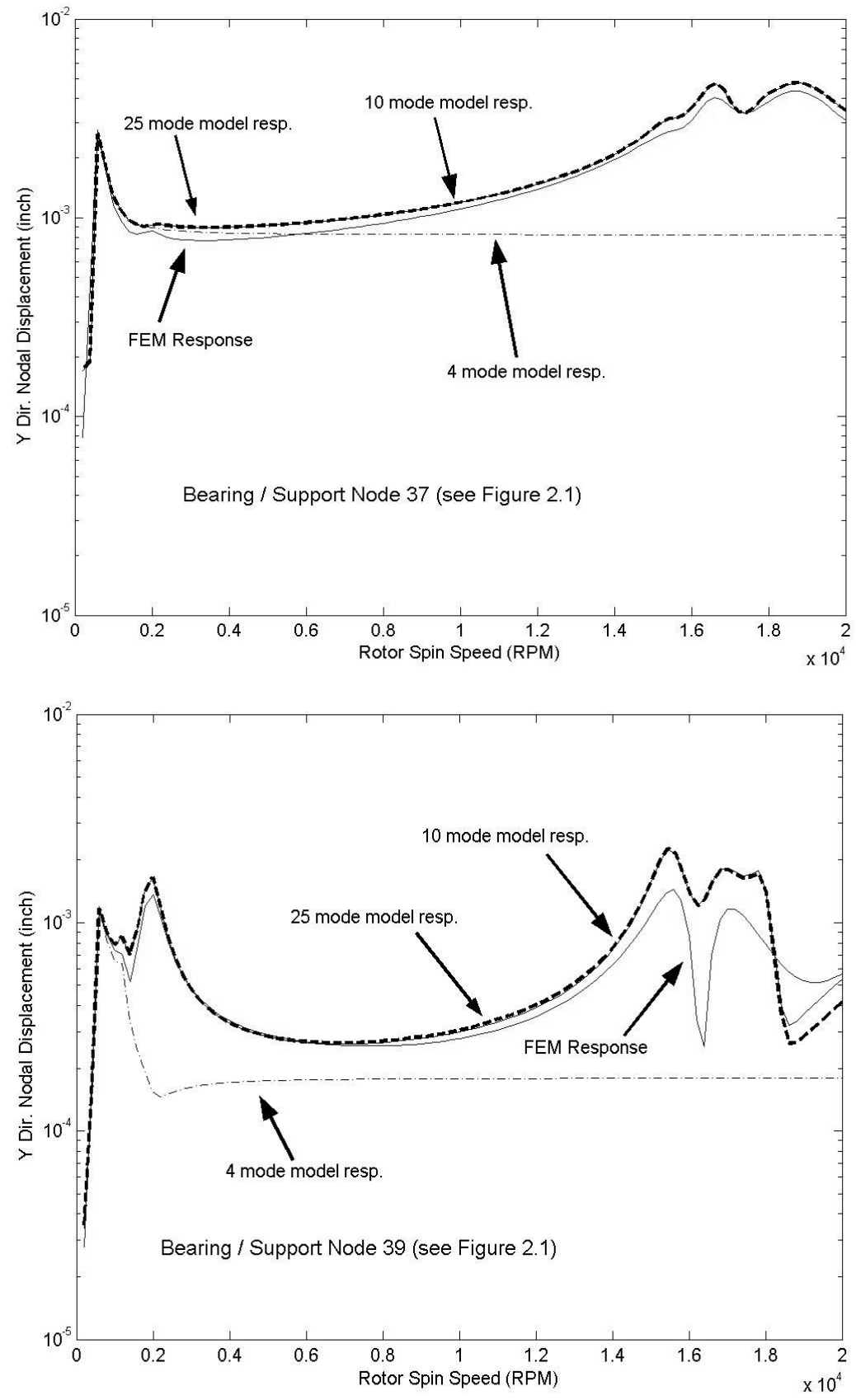

Figure 2.5. Steady state imbalance response comparison of 4, 10, and 25 degree of freedom (DOF) reduced order models for two different bearing/support locations. Imbalance has an eccentricity of 0.001 inch located at the fan. 


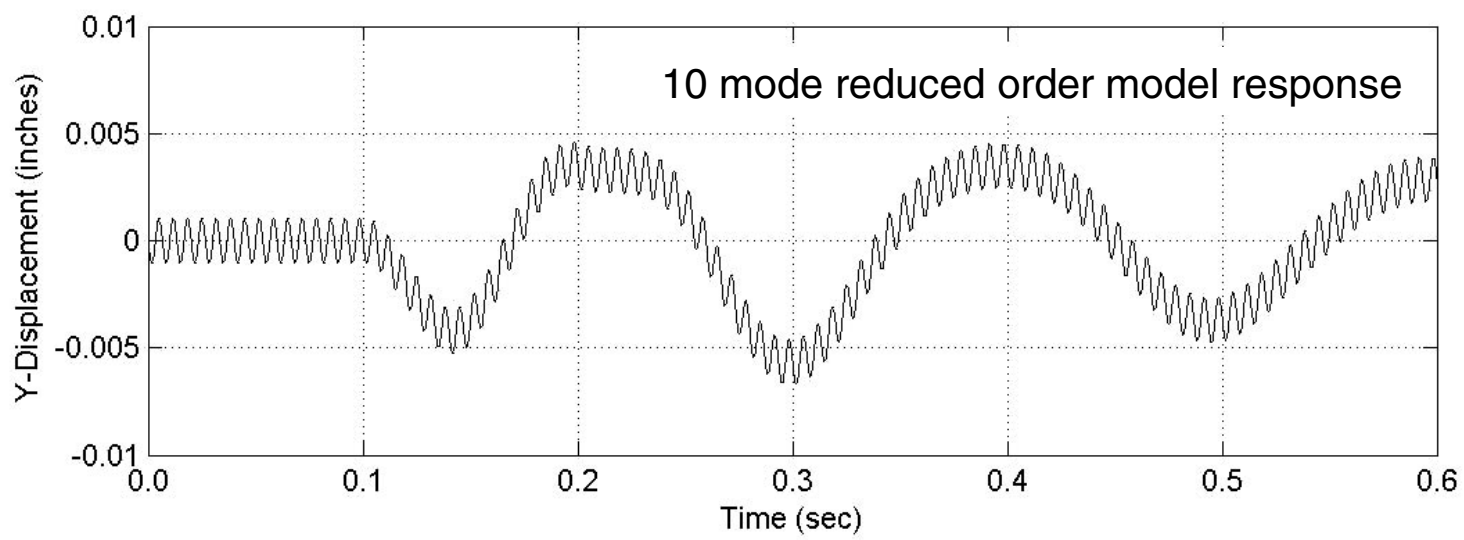

a)
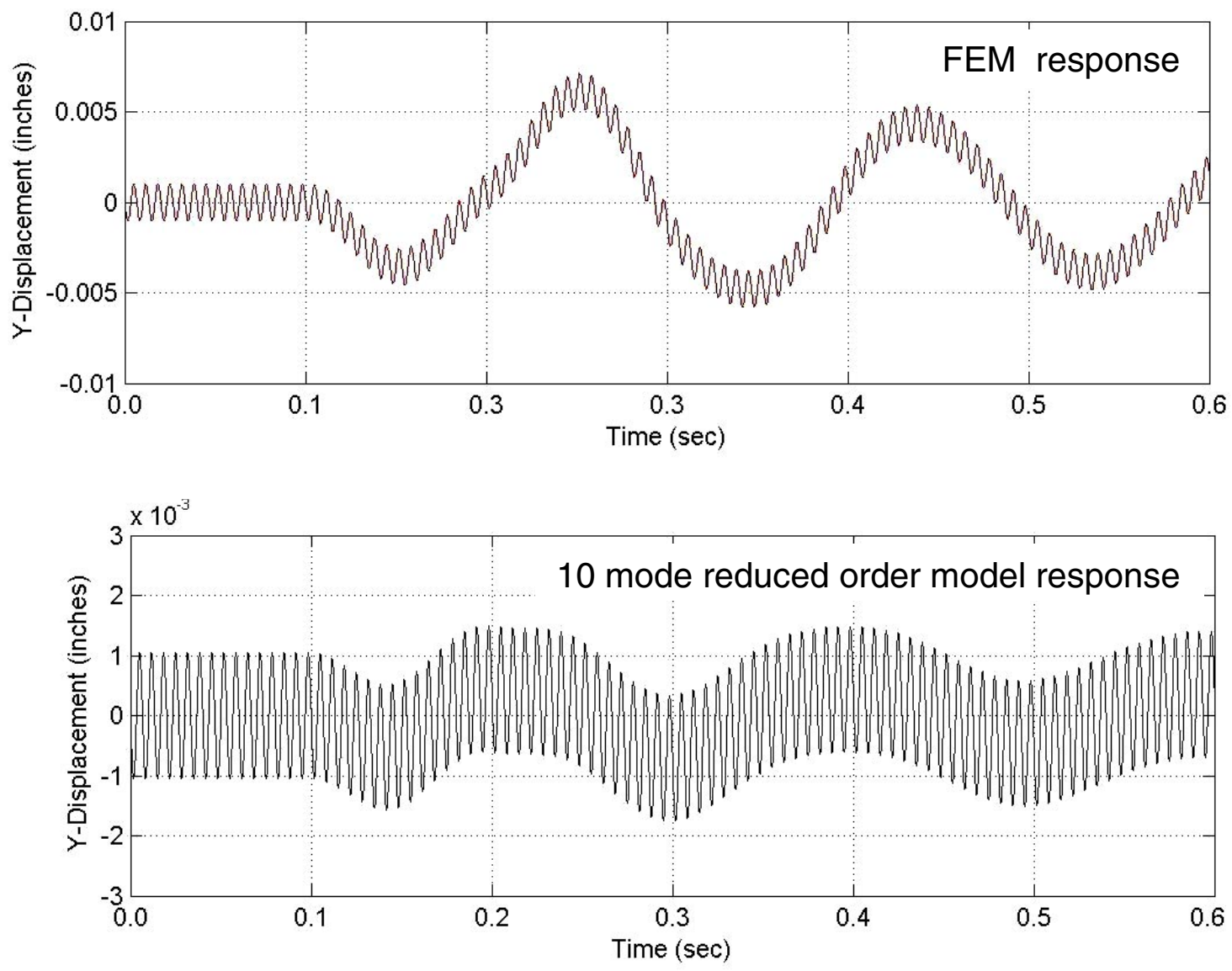

b)

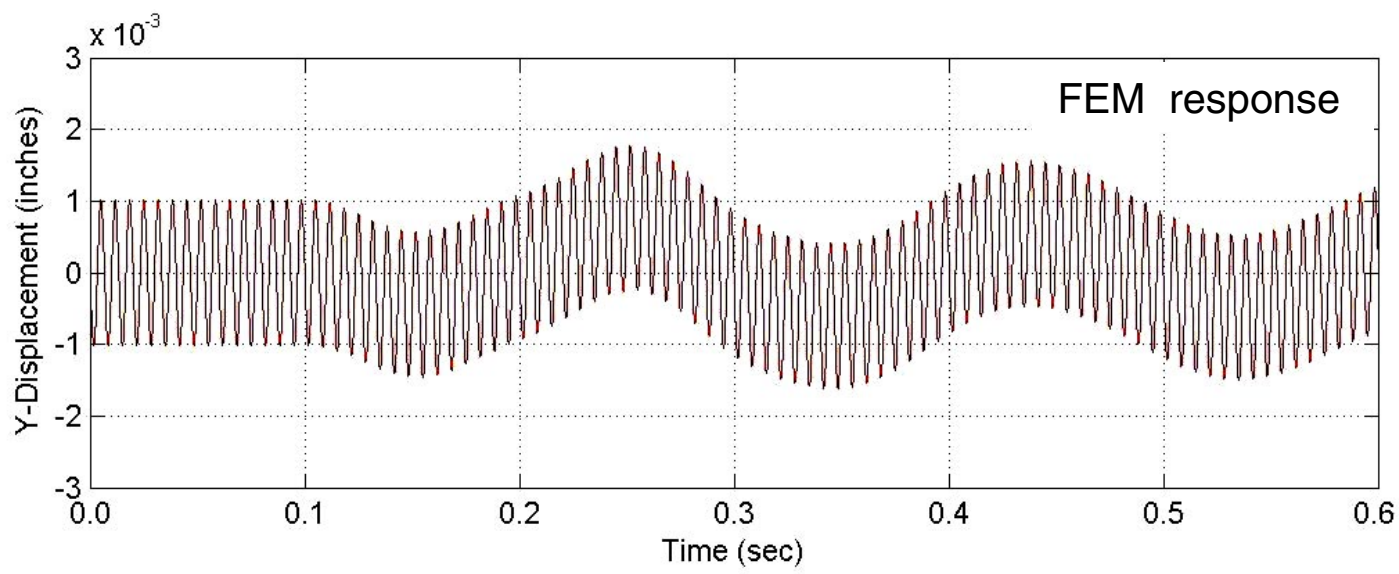

Figure 2.6. Response at bearing/support location 37 to (a) a "large" FOD event $\left(\mathrm{m}_{\mathrm{FO}}=2 \mathrm{lbm}\right)$, and $(\mathrm{b})$ a "small" FOD event $\left(\mathrm{m}_{\mathrm{FO}}=0.25 \mathrm{lbm}\right)$. 
a)
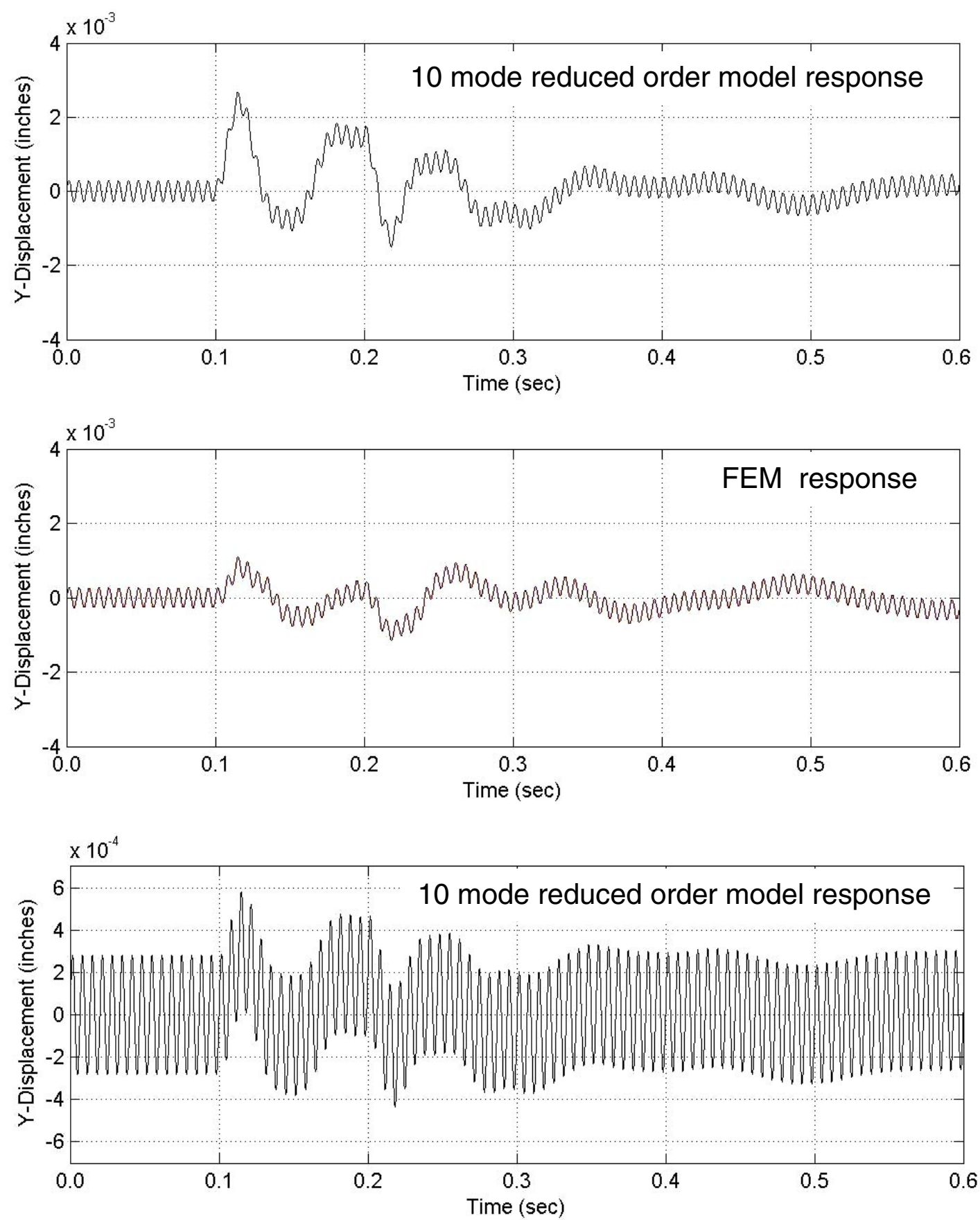

b)

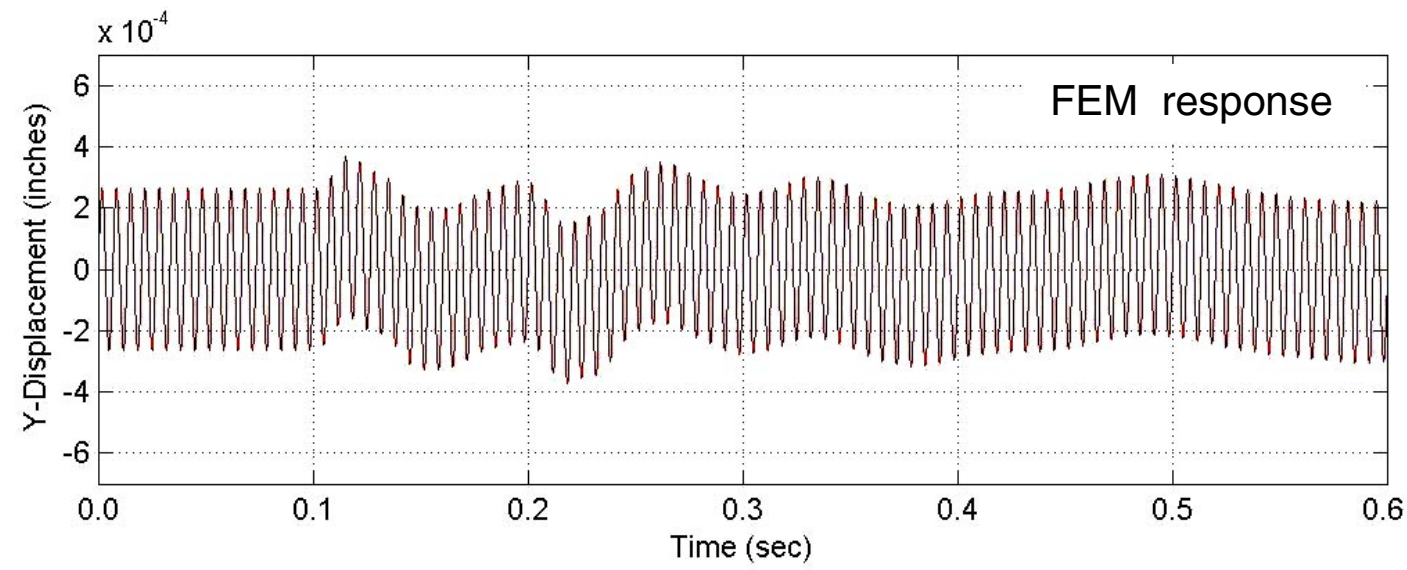

Figure 2.7. Response at bearing / support location 39 to (a) a "large" FOD event $\left(\mathrm{m}_{\mathrm{FO}}=2 \mathrm{lbm}\right)$ and $(\mathrm{b})$ a "small" FOD event $\left(\mathrm{m}_{\mathrm{FO}}=0.25 \mathrm{lbm}\right)(\mathrm{b})$. 
the ROM uses constant modal damping ratios and natural frequencies over the full range of operating speeds.

For both locations, the change in the vibration signal due to the large FOD event is easily discernable from the nominal vibration signal due to inherent imbalance alone. For the small FOD events, there is less of a difference from the normal operating characteristic. For smaller FOD events with the presence of sensor or process noise (which would be the case in an actual engine) the event could easily be masked. Thus, the signal analysis technique employed to detect such an event must be capable of identifying the characteristic vibration signature in the presence of process and sensor noise.

\subsection{Optimal Sensor Placement for FOD event detection.}

Signal processing techniques that provide information concerning the internal modes (i.e., states ) of a system require that these state variables be observable using the available sensor suite [17]. For FOD-event detection, the vibration sensor (e.g., accelerometer) signal must contain the modal response of the rotor in the frequency range of interest. The modes of a system are observable if and only if the matrix

$$
\mathrm{O}=\left[\begin{array}{c}
\mathrm{C} \\
\mathrm{CA} \\
\vdots \\
\mathrm{CA}^{\mathrm{n}-1}
\end{array}\right]
$$

known as the observabilty matrix, has rank $n$, where $n$ is the dimension of the state space of the linear time invariant system under consideration. For the 10 mode ROM representing the rotorbearing system shown in Figure 2.1 (with nodes 37 through 41 as candidate accelerometer locations) the system is completely observable. To determine the optimal (or worst case) accelerometer location for FOD event detection, a measure of the degree of observability of a system for a given sensor arrangement must be determined. One method suggested in [17] requires calculation of the Observability Grammian to determine which states, starting from a specified set of initial conditions, have an influence on the output energy $\mathrm{E}(\mathrm{x}(0))$ of the system over all time. 
Consider the following measure of the output energy at some initial condition $\mathrm{x}(0)$ for the system of Equation 2.3 under observation with no external input

$$
\mathrm{E}(\mathrm{x}(0))=\int_{0}^{\infty}\|\mathrm{y}(\mathrm{t})\| \mathrm{dt}=\int_{0}^{\infty} \mathrm{y}(\mathrm{t})^{\mathrm{T}} \mathrm{y}(\mathrm{t}) \mathrm{dt}=\mathrm{x}(0)^{\mathrm{T}} \mathrm{Q} \mathrm{x}(0)
$$

where the Observability Grammian is defined as

$$
\mathrm{Q}=\int_{0}^{\infty} \mathrm{e}^{\mathrm{A}^{\mathrm{T}} \mathrm{t}} \mathrm{C}^{\mathrm{T}} \mathrm{Ce}^{\mathrm{At}} \mathrm{dt}
$$

For a stable system, the existence of Equation 3.3 is guaranteed and Q may be found by solving the following Lyapunov equation

$$
\mathrm{A}^{\mathrm{T}} \mathrm{Q}+\mathrm{QA}+\mathrm{C}^{\mathrm{T}} \mathrm{C}=0
$$

For a reduced number of accelerometers (reduced relative to the initial set i.e., accelerometers 37 through 41 in Figure 2.1) the system is observable if and only if $Q$ is positive definite. With observability established for the reduced sensor suite system, Equation 3.2 is used to determine the output energy contribution of each state variable. Large output energies correspond to easily observable state variables (modes). The optimal suite of sensors would naturally be that with the (relatively) largest output energies for the modes needed to identify a FOD event. Consider the calculation of Equation 3.2 for locations 37 and 40. With the entry in the initial state vector (i.e., $\mathrm{x}(0))$ for a specified mode set to 1.0 and the initial conditions for each of the other modes set to 0.0 , $\mathrm{E}(\mathrm{x}(0))$ for each mode observed separately is simply the diagonal entry of $\mathrm{Q}$ corresponding to each mode. Thus, a judgment as to the optimal placement of the accelerometers may be made based on the diagonal entries of $\mathrm{Q}$ alone. For locations 37 and 40 


$$
\operatorname{diag}[Q]_{\text {Node } 37}=\left[\begin{array}{r}
4.1211 \mathrm{e}-003 \\
5.1742 \mathrm{e}-003 \\
2.3575 \mathrm{e}-005 \\
9.3601 \mathrm{e}-007 \\
4.4442 \mathrm{e}-006 \\
3.9526 \mathrm{e}-004 \\
2.5111 \mathrm{e}-003 \\
3.6104 \mathrm{e}-004 \\
5.0943 \mathrm{e}-003 \\
9.8736 \mathrm{e}-004
\end{array}\right] \quad \operatorname{diag}[\mathrm{Q}]_{\text {Node } 40}=\left[\begin{array}{c}
3.6160 \mathrm{e}-007 \\
3.1261 \mathrm{e}-005 \\
1.4738 \mathrm{e}-005 \\
6.9672 \mathrm{e}-003 \\
4.4159 \mathrm{e}-004 \\
4.3813 \mathrm{e}-004 \\
1.6479 \mathrm{e}-004 \\
2.9526 \mathrm{e}-004 \\
2.2466 \mathrm{e}-008 \\
1.0822 \mathrm{e}-004
\end{array}\right]
$$

which, due to the higher observation energies associated with the first three modes, implies that placement of an accelerometer at location 37 may be more appropriate for detecting a FOD event. Upon performing the calculation of Equation 3.2 for nodes 37 through 41 as candidate accelerometer locations, node 37 was determined to be the preferred location with node 40 being the least preferred. Thus, the analysis (i.e., feature extraction) technique selected should be applied to the signal generated by "accelerometer 37 " in order to have the highest likelihood of detecting a FOD event. However, placement of a sensor at the optimal location may not be physically attainable, thus it is desirable that this same technique should be robust enough to detect the event at a suboptimal (possibly the most limiting) location. For some systems this conclusion may be drawn directly from physical intuition. For more complex systems (which may not easily lend themselves to physical intuition) the analytical treatment presented above provides a quantitative measure for optimal sensor placement.

\subsection{FOD Event Detection Via Rotor Bearing Vibration Signal Analysis}

Consider the simulated bearing accelerometer signals shown in Figure 4.1. To demonstrate the robustness of the WF extraction technique, the analyses described below were performed on the signal from the most limiting accelerometer location on the rotor bearing system considered, which was determined from the sensor placement analysis of section 3.0 to be at node 40 (Figure 2.1). This location would result in the weakest signal and necessarily correspond to the most difficult 
location for FOD event detection. At 3.44 seconds, a $0.5 \mathrm{lbm}$ foreign object hits the fan disk with a speed of $300 \mathrm{mph}$ (parallel to the Z-axis in Figure 2.3) at a radius of 20 inches. The event is modeled as a pulse of width 0.04 seconds, with a magnitude determined using the method presented in Section 2.2. A fan disk eccentricity of 0.001 inches is assumed. As shown in Figure $4.1 \mathrm{a}$, the event is barely noticeable in the time trace for a noise-free situation. However accelerometer signals on in-service engines are typically noisy. In addition to "process noise" i.e., random motion of the aircraft due to wind gusts and compensating maneuvers being transmitted from the airframe to the engine, there is a significant amount of sensor noise which may mask the occurrence of a FOD event. Figure 4.1b shows the accelerometer signal at location 40, with a signal-to-noise ratio of approximately $3.5(11 \mathrm{~dB})$. Observation of the signal shows no well-defined point in time at which one would identify a FOD event occurrence.

a)
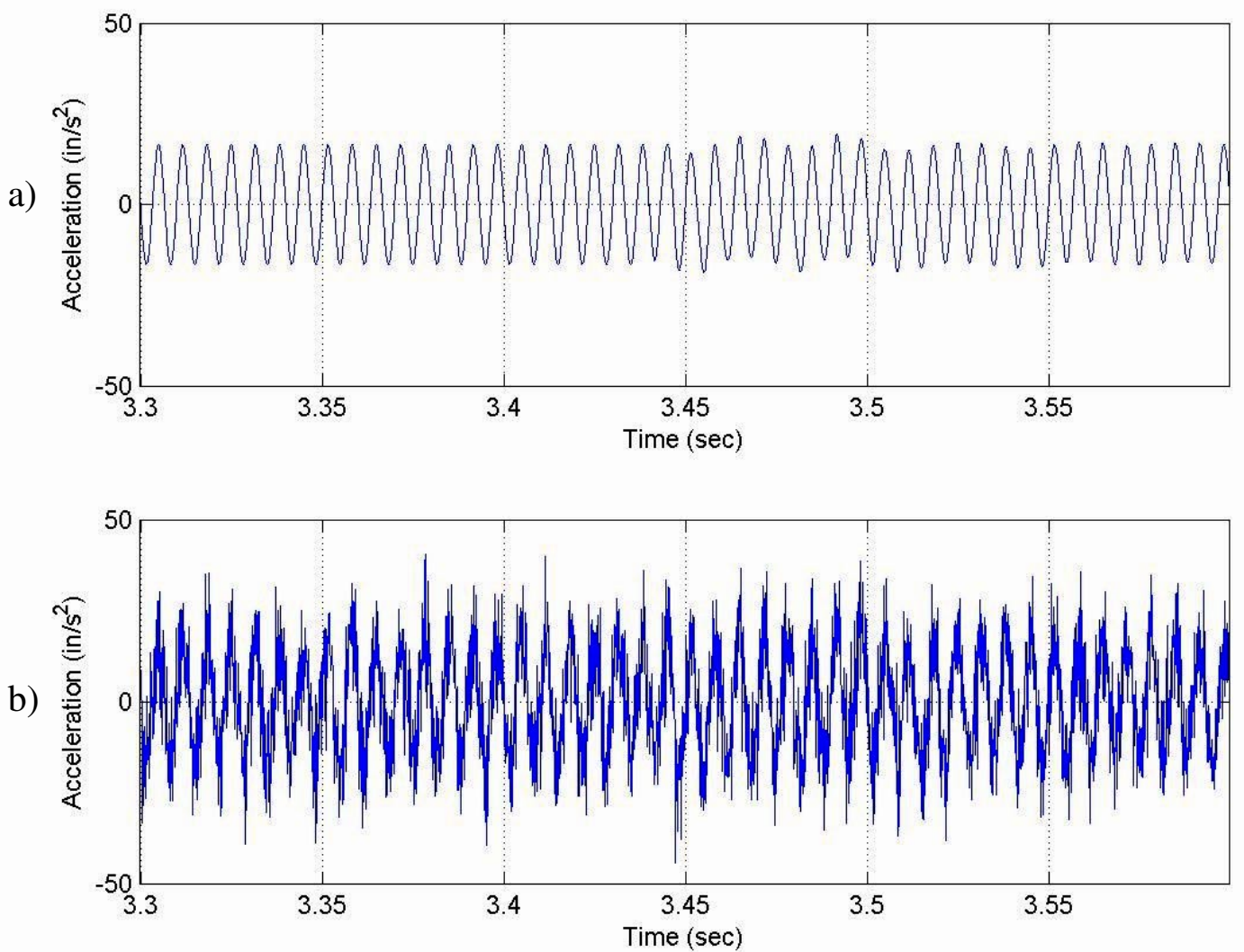

Figure 4.1. Bearing 40 accelerometer output signal corresponding to a FOD event. a) Noise free system response. b) System response with process and sensor noise. 


\subsection{FOD event Detection using Fourier Analysis of Rotor Bearing Vibration Signals}

Vibration signal analysis is an invaluable tool for identifying mechanical component problems. The most utilized tool in vibration analysis i.e., the Fourier transform, essentially assumes that the signals being analyzed are of infinite duration $[18,19]$. When the continuous-time Fourier transform

$$
\mathrm{Y}(\mathrm{F})=\int_{-\infty}^{\infty} \mathrm{y}(\mathrm{t}) \mathrm{e}^{-\mathrm{j} 2 \pi \mathrm{Ft}} \mathrm{dt}
$$

or, more practically, its discrete-time counterpart

$$
Y(f)=\sum_{n=-\infty}^{n=\infty} y(n) e^{-j 2 \pi f n}
$$

is applied to a signal of finite duration, spectral leakage effects can significantly reduce the resolution of the corresponding power (frequency) spectrum given by

$$
|Y(f)|^{2}=\left|\sum_{n=-\infty}^{n=\infty} y(n) e^{-j 2 \pi f n}\right|^{2}
$$

Windowing of the original signal aids in mitigating the effects of finite signal length (spectral leakage), however if the component of the signal being analyzed has "compact support" (e.g., an impulse due to a FOD-event induced structural response), windowing of the signal may not significantly aid in identifying the occurrence of the event in time due to the Fourier transform basis functions i.e., sinusoids, being themselves functions of infinite support and limited in their ability to decompose such a finite-duration signal. The short-time Fourier transform (and the corresponding time-dependant power spectrum) uses a windowed version of $y(n)$ to compute $Y(f)$ in an attempt to localize a change in a signal over time [19]. The time-dependant power spectrum 
for the noise-free signal (Figure 4.2 a) shows a significant change at approximately 3.3 seconds, which disappears as time progresses. The time-dependant power spectrum of the noisy signal (Figure 4.2 b) shows no noticeable change in time, with the effect of the FOD event "buried" in the spectra due to the noise. Thus, there is a need for an alternative signal analysis technique for FOD event detection.

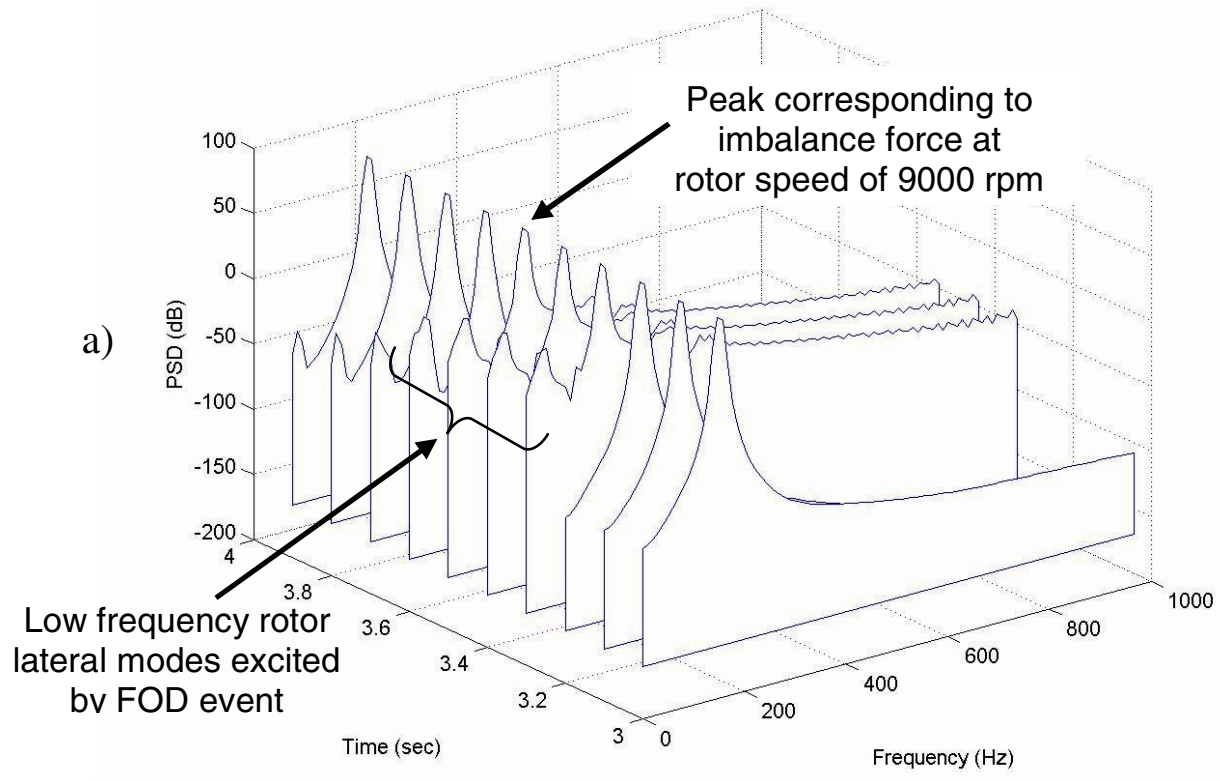

Low frequency rotor lateral

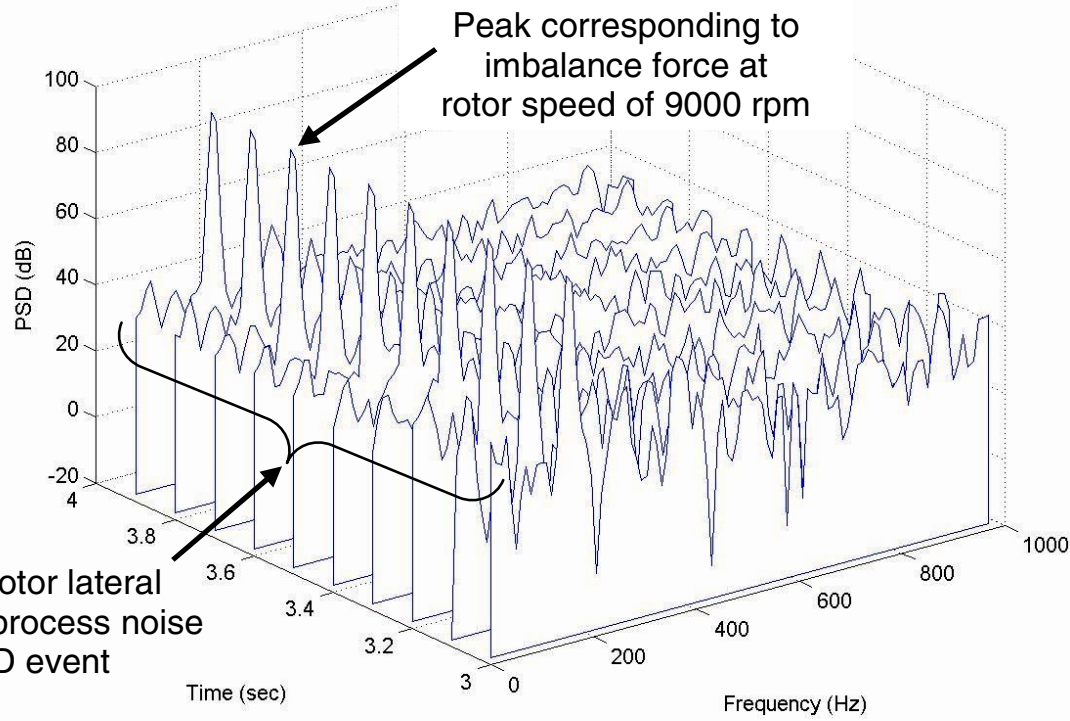

Figure 4.2. Power spectra of bearing 40 accelerometer output signal corresponding to a FOD event. a) Noise free system response. b) System response with process and sensor noise. 


\subsection{FOD event Detection using Wavelet Analysis of Rotor Bearing Vibration Signals}

Over the past decade the discrete time wavelet transform (DTWT) has been applied to a wide range of signal analysis problems e.g., de-noising of signals as well as time localization and reconstruction of short duration changes [8]. Because of these characteristics, the DTWT is considered to be a viable candidate for identifying a short duration change in a bearing vibration signal due to a FOD event corrupted by noise.

The DTWT is the discrete-time counterpart of the continuous-time wavelet transform

$$
\operatorname{CWT}(\mathrm{a}, \tau)=\frac{1}{\sqrt{\mathrm{a}}} \int \mathrm{y}(\mathrm{t}) \Psi\left(\frac{\mathrm{t}-\tau}{\mathrm{a}}\right) \mathrm{dt}
$$

where $\Psi(\mathrm{t})$ is the basic or mother wavelet and $\Psi((\mathrm{t}-\tau) / \mathrm{a}) / \sqrt{\mathrm{a}}$ are the wavelet basis functions which are scaled via the parameter a (by compressing or stretching the mother wavelet) and shifted in time by $\tau$. The operation performed in equation 4.4 on the original signal $y(t)$ may be interpreted as the cross correlation of the signal $\mathrm{y}(\mathrm{t})$ with $\Psi(\mathrm{t} / \mathrm{a}) / \sqrt{\mathrm{a}}$, shifted by $\tau / \mathrm{a}$ [18]. Thus, the CWT computes the component of $\mathrm{y}(\mathrm{t})$ that is similar to $\Psi(\mathrm{t} / \mathrm{a}) / \sqrt{\mathrm{a}}$. If little (or no) similarity exists between the two, then the CWT will be small (or zero). Larger values of CWT indicate better correlation. Figure 4.3 presents an overview of the Wavelet Transform process with multiple scale decomposition. The wavelet family used is the Daubechies family.

Typically, the resulting data is presented in terms of time (or $\mathrm{k}$ if in discrete time) and scale (i.e., coefficient) of the chosen wavelet transform. "Pseudo" frequency components of $y(t)$, corresponding to the scale of the constituent wavelets, $\mathrm{F}_{\mathrm{m}}$, are obtained by the following expression [20]

$$
\mathrm{F}_{\mathrm{m}}=\frac{\mathrm{TF}_{\mathrm{c}}}{\mathrm{m}}
$$


where $\mathrm{m}$ is the scale, $\mathrm{T}$ is the sampling interval, and $\mathrm{F}_{\mathrm{c}}$ is the wavelet center frequency calculated by taking the maximum of the modulus of the wavelet's Fourier transform.

Most of the functions for $\Psi(\mathrm{t})$ have been developed over the past two decades with the Haar wavelet being the first documented function to be used in this context[19]. Choice of $\Psi(t)$ is heavily dependant on the nature of the signal (or a localized feature of a signal) being analyzed. For example, if a vibration signal were to be analyzed to determine whether a FOD event had occurred, one would expect to see an impulse-like localized feature embedded in a normally noisy sinusoidal signal. Intuitively, one would choose a wavelet that had an impulse-like character as opposed to one that resembled a step function, as is the case with the Haar wavelet mentioned previously.

Inverse Wavelet transform gives signal decomposition in terms of time and scale (pseudo frequency)

\title{
Simulated Bearing Acceleration Signal
}
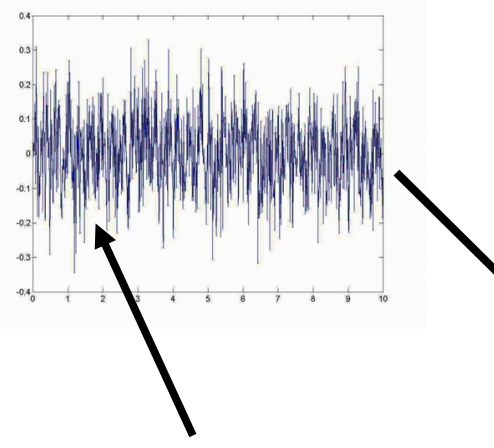

FOD-event occurrence selected to "fit" application
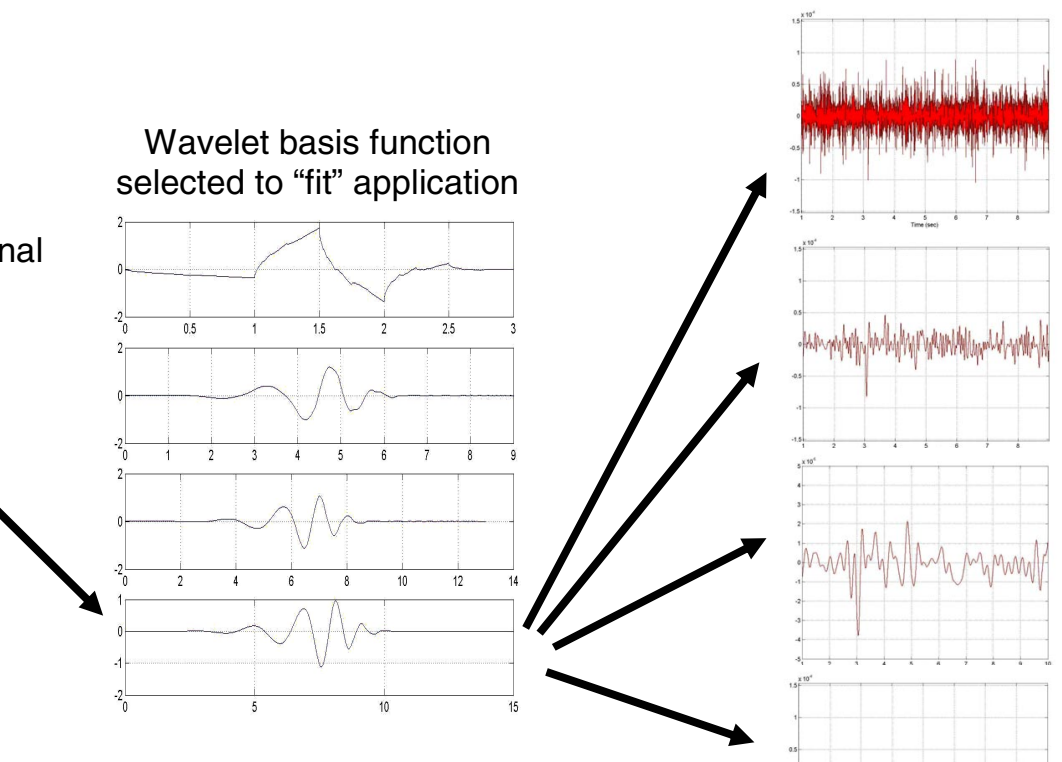

(1)


where $\mathrm{m}$ is the scale (degree of dilation) and $\mathrm{n}$ corresponds to the net translation in time (in terms of the number of time $\tau_{\mathrm{o}}$ ) of the wavelet at a specific scale. For scale $m=0$, the coefficients of the so-called scaling function, from which all of the wavelets in a given family are related, are

$$
\operatorname{DTWTA}(0, \mathrm{n})=\sum_{\mathrm{k}} \mathrm{y}(\mathrm{k}) \varphi\left(\mathrm{k}-\mathrm{n} \tau_{\mathrm{o}}\right)
$$

$\varphi\left(\mathrm{k}-\mathrm{n} \tau_{0}\right)$ is typically determined via iteration using the following dilation equation

$$
\varphi(\mathrm{k})=\sum_{\mathrm{n}=0}^{\mathrm{N}-1} \mathrm{c}_{\mathrm{n}} \varphi\left(2 \mathrm{k}-\mathrm{n} \tau_{0}\right)
$$

where $\mathrm{N}$ is the number of terms in $\varphi(\mathrm{k})$. The scaling function $\varphi(\mathrm{k})$ determines the character of the wavelet. The characteristic of interest in the signal being analyzed typically dictates the form of the wavelets used. A wavelet $\psi(\mathrm{k})$ is related to it's associated $\varphi(\mathrm{k})$ via

$$
\psi(\mathrm{k})=\sum_{\mathrm{n}=0}^{\mathrm{N}-1}(-1)^{\mathrm{n}} \mathrm{c}_{\mathrm{n}} \varphi\left(2 \mathrm{k}+\mathrm{n} \tau_{0}-\mathrm{N}+1\right)
$$

Equation 4.9 is also a dilation equation with $\psi(\mathrm{k})$ referred to as a dilation wavelet [19]. The scaling function, it's dilates, the corresponding wavelets and their dilates are orthogonal to one another and therefore constitute a set of functions by which an arbitrary function may be built [19], completely analogous to the Fourier transform and series. The base value of scaling parameter, $\mathrm{a}_{\mathrm{o}}$, and the time shift, $\tau_{\mathrm{o}}$, are typically set equal to 2 and 1 respectively for computational efficiency, analogous to the Fast Fourier Transform (FFT).

The convolution of Equations 4.6 and 4.7 is commutative i.e., 


$$
\begin{gathered}
\operatorname{DTWTA}(0, \mathrm{n})=\sum_{\mathrm{k}} \varphi(\mathrm{k}) \mathrm{y}\left(\mathrm{k}-\mathrm{n} \tau_{\mathrm{o}}\right) \\
\operatorname{DTWTD}(\mathrm{m}, \mathrm{n})=\mathrm{a}_{\mathrm{o}}-\frac{\mathrm{m}}{2} \sum_{\mathrm{k}} \psi(\mathrm{k}) \mathrm{y}\left(\mathrm{a}_{\mathrm{o}}-\mathrm{m}_{\mathrm{k}}-\mathrm{n} \tau_{\mathrm{o}}\right)
\end{gathered}
$$

Thus, the discrete-time wavelet transform may be viewed as a filtering operation with $\varphi(\mathrm{k})$ containing the coefficients of a low-pass Finite Impulse Response (FIR) filter and $\psi(\mathrm{k})$ the coefficients of a high-pass FIR filter. The coefficients corresponding to the low-frequency portion of the input signal i.e., approximation coefficients (Equation 4.10), and the high-frequency detail coefficients (Equation 4.11) at a given scale in a wavelet decomposition are provided by successive low pass and high pass filtering operations respectively. Reconstruction of the approximations and details at a specified scale $\mathrm{m}$ is performed via the corresponding inverse wavelet transform

$$
\begin{aligned}
& \mathrm{D}_{\mathrm{m}}(\mathrm{k})=\sum_{\mathrm{n}} \operatorname{DTWTD}(\mathrm{m}, \mathrm{n}) \psi_{\mathrm{m}, \mathrm{n}}(\mathrm{k}) \\
& \mathrm{A}_{\mathrm{m}}(\mathrm{k})=\sum_{\mathrm{n}} \operatorname{DTWTA}(\mathrm{m}, \mathrm{n}) \varphi_{\mathrm{m}, \mathrm{n}}(\mathrm{k})
\end{aligned}
$$

and is implemented via banks of reconstruction or synthesis filters. Figure 4.4 presents a 2-scale DTWT-based signal analysis and synthesis using an FIR quadrature mirror filter bank. Locations in the filter bank correspond to the signal characteristics of interest (details or approximations). Scaling is accomplished by downsampling after high or low pass filtering. Successive upsampling and filtering performs the reconstruction. When the reconstruction filter coefficients correspond to the quadrature mirror filter of the decomposition filter, perfect signal reconstruction is guaranteed [21]. This is the practical implementation of the discrete-time wavelet transform algorithm developed by Mallat [22, 23, 24]. The information gained from the decomposition depends on the application e.g., a signal may be "denoised" by omitting the detail from one or more scales during the reconstruction. As well, abrupt changes in the signal e.g., a FOD event-induced accelerometer response, might be detected by observing one or more of the approximations. 
Figure 4.5 presents a wavelet analysis of the signal analyzed in Section 4.1, the noise-free bearing accelerometer signal at location 40 . The Daubechies 8 wavelet was chosen (a subjective choice) for the analysis due to its correspondence to the signal characteristic of interest. Observing the approximation at scale 8 (Figure 4.5 b) demonstrates the wavelet's ability to determine the location in time of the event. Several other approximations and details at various scales (not shown) also revealed the occurrence of a FOD event. The analysis of the noisy signal at the same scale's approximation (Figure 4.6), however, illustrates that the wavelet chosen (as well as several other wavelets tested, not presented here), may have difficulty highlighting a subtle change buried in a low signal-to-low noise ratio (SNR = 3.5) signal. Additional "conditioning" of the decomposed signal is required.

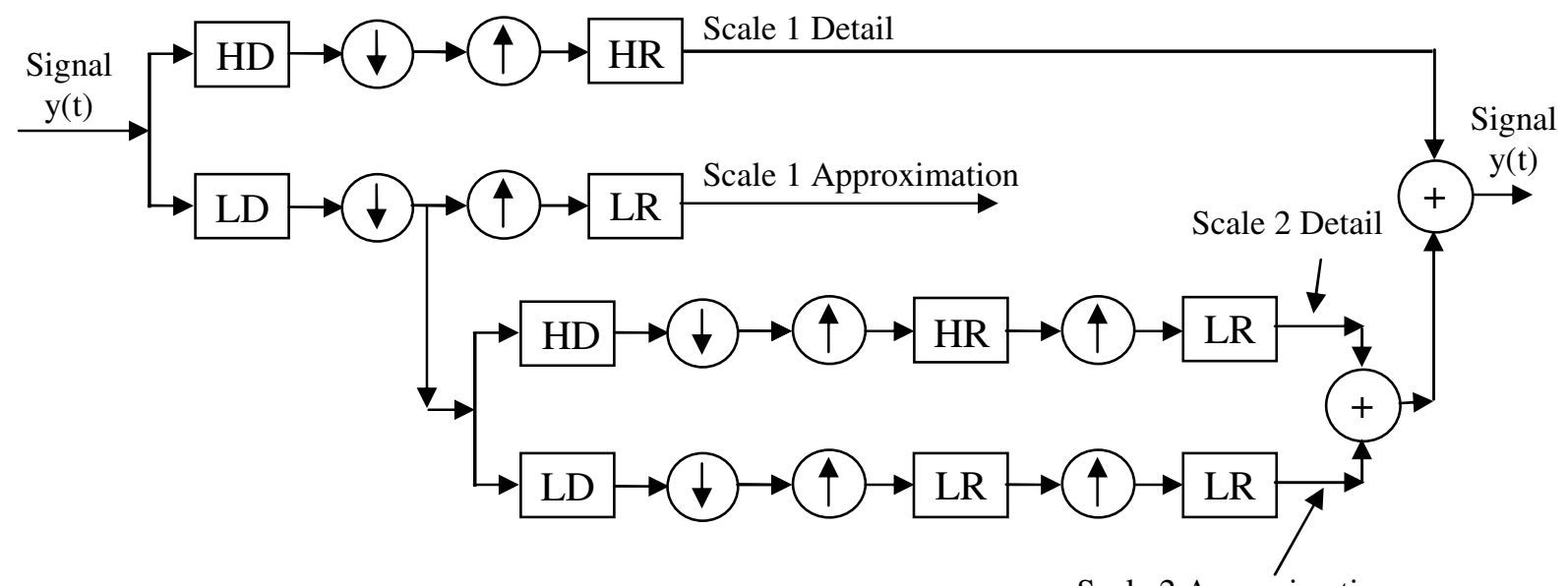

Scale 2 Approximation

\begin{tabular}{|c|c|c|}
\hline LR & $\begin{array}{c}\text { Low Pass Reconstruction FIR } \\
\text { Filter }\end{array}$ & $\begin{array}{l}\text { Downsample } \\
\text { by a Factor of } 2\end{array}$ \\
\hline LD & $\begin{array}{c}\text { Low Pass Decomposition FIR } \\
\text { Filter }\end{array}$ & \\
\hline HR & $\begin{array}{l}\text { High Pass Reconstruction FIR } \\
\text { Filter }\end{array}$ & Upsample \\
\hline HD & $\begin{array}{l}\text { High Pass Decomposition FIR } \\
\text { Filter }\end{array}$ & \\
\hline
\end{tabular}

Figure 4.4. Example of a 2-scale DTWT-based signal analysis and synthesis using an FIR quadrature mirror filter bank. 
a)

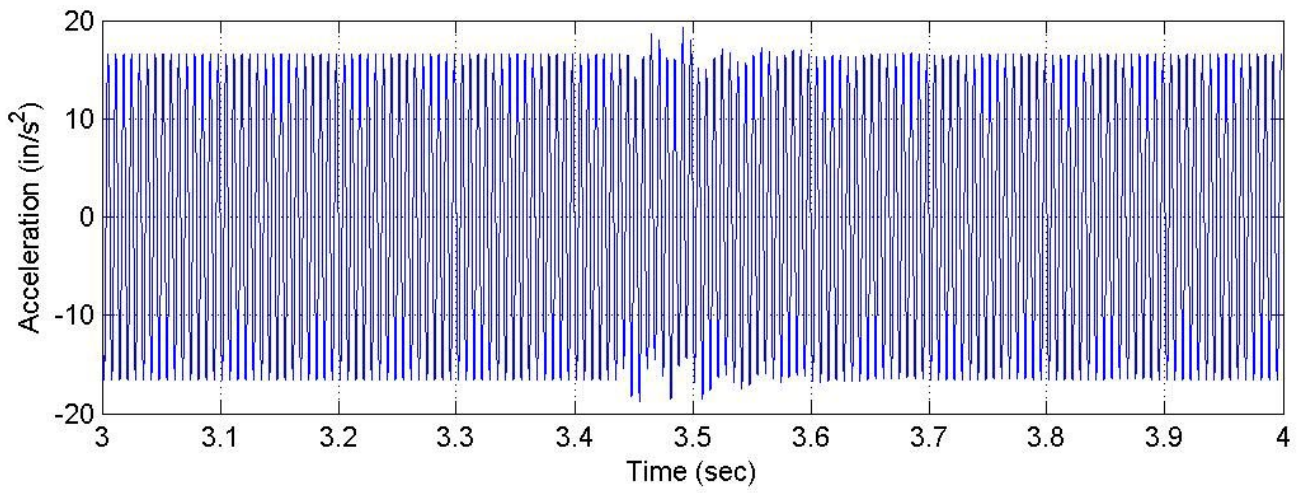

b)

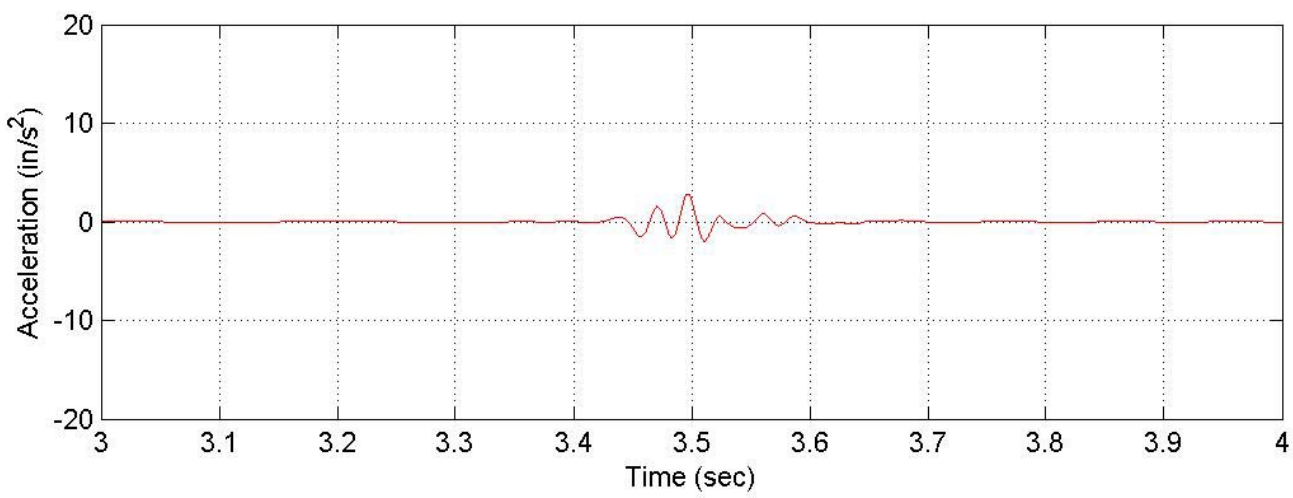

Figure 4.5. Wavelet analysis of noise-free bearing accelerometer signal at location 40 . a) accelerometer signal. b) Corresponding Daubechies 8 wavelet inverse transform, scale 8 approximation.

a)
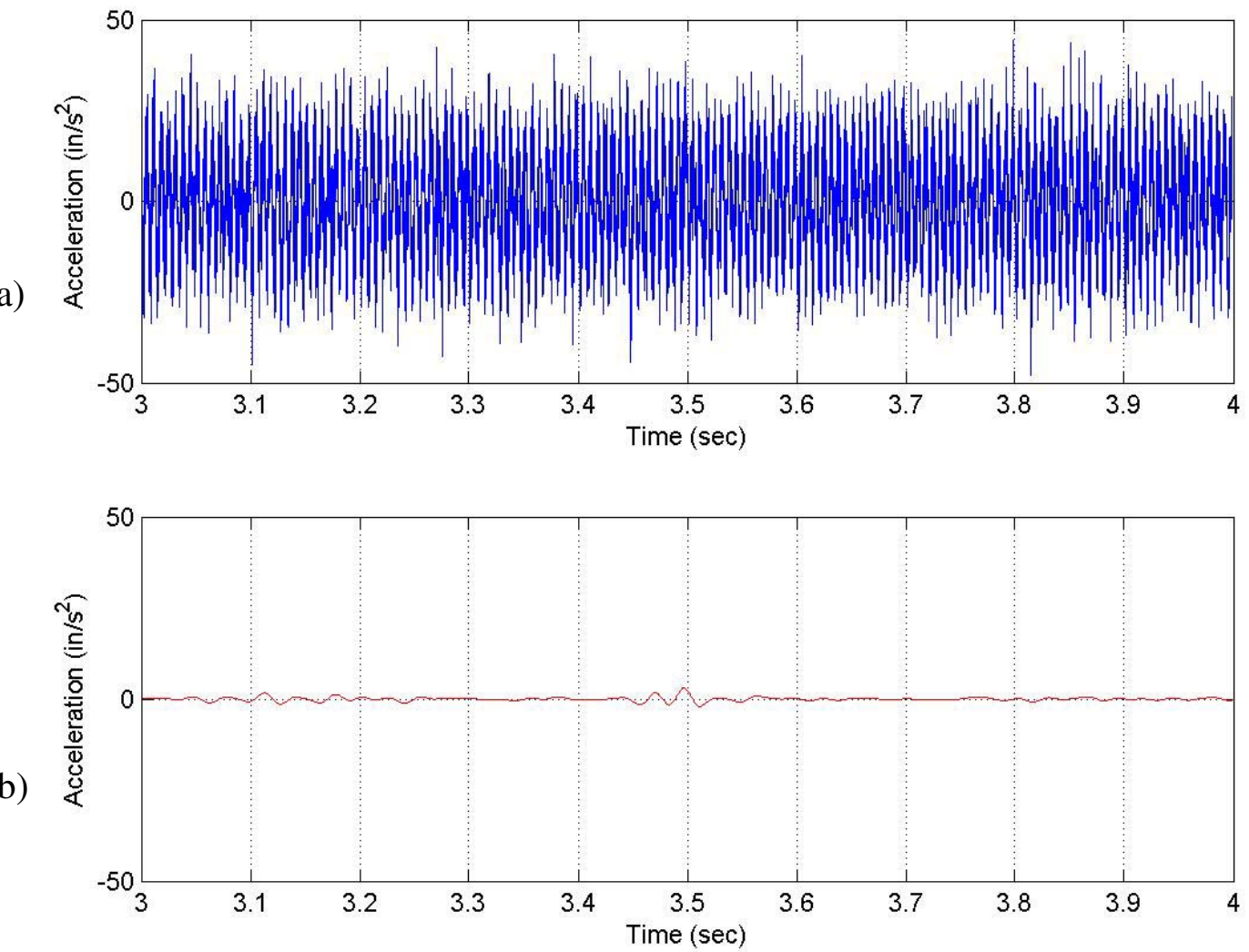

Figure 4.6. Wavelet analysis of noisy bearing accelerometer signal at location 40.

a) accelerometer signal. b) Corresponding Daubechies 8 wavelet inverse transform, scale 8 approximation. 
Abrupt changes in an otherwise smooth signal will correspond to a localized change in the signal derivative with respect to time (or some space-related dependant variable depending on the application). The more abrupt the change, the larger the local value of the derivative with respect to time. Additionally, for the same change the value of higher order derivatives

$$
\frac{d^{n} y(t)}{d t^{n}}
$$

will provide a frequency-dependant gain i.e., the more abrupt the signal change, the larger the gain. This quality of the derivative is more easily observed in the frequency domain by taking the Laplace transform of Equation 4.14 and setting $s=j \omega$

$$
L\left\{\frac{d^{n} y(t)}{d t^{n}}\right\}_{S=j \omega}=(j \omega)^{n} y(j \omega)
$$

The corresponding frequency-dependant magnitude is

$$
\left.\operatorname{MAG}\left((j \omega)^{\mathrm{n}} \mathrm{y}(\mathrm{j} \omega)\right)=\omega^{\mathrm{n}} \operatorname{MAG}^{\mathrm{M}} \mathrm{y}(\mathrm{j} \omega)\right)
$$

Thus, multiple differentiation in the time domain provides an " $\mathrm{s}$ " " multiplication factor in the frequency domain. The higher frequency characteristics of a signal (e.g., a FOD-event would be classified as a high-frequency event) would have a significantly higher gain relative to the lowfrequency components. It would seem that in a noise-free signal, the occurrence of a FOD-event resulting in an impulsive input to the turbofan rotor of the present study could easily be identified using this technique. Multiple differentiation of noisy signals is typically avoided in most signal processing applications due to the amplification provided by Equation 4.16. Indeed, multiple differentiation of the signal shown in Figure 4.6a would make identification of a FOD-event virtually impossible, primarily due to amplification of the noise. 
Mallat [25] proposed a technique for identifying a wavelet specifically designed for edge detection in computer vision systems. A signal (or 2-D image in the original application) is passed through a smoothing function (e.g., a low pass filter) and differentiated multiple times. The combination of smoothing and differentiation results in a wavelet customized to the application. For this research, the technique was adapted to identify the FOD event induced short-time change in accelerometer signals. The smoothing filter chosen for the present investigation is the Daubechies-8 wavelet decomposition. As shown in Figure 4.7, the accelerometer signal is passed through an approximation filter bank three times and subsequently passed through a detail filter. This provides

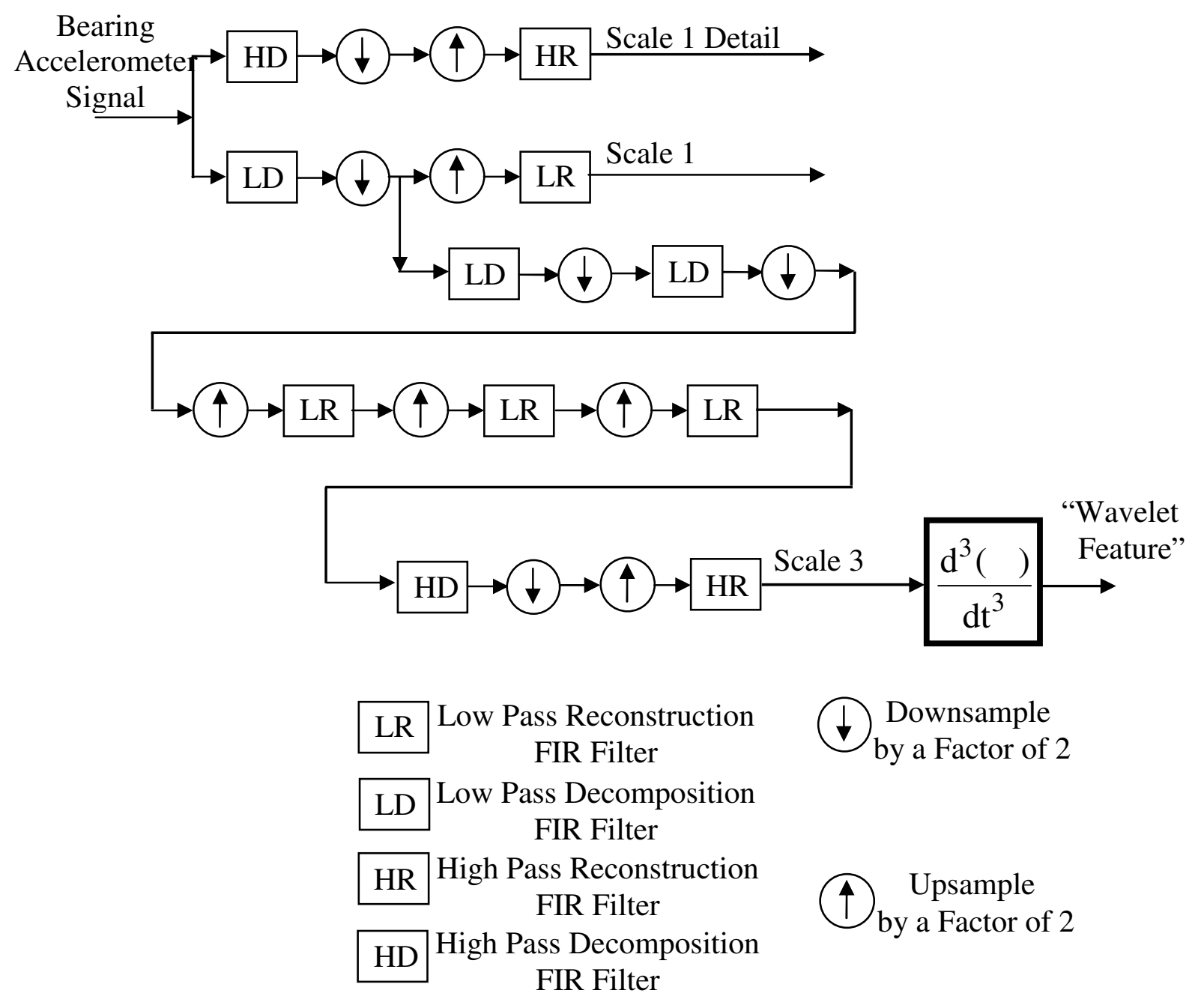

Figure 4.7. Wavelet transform-based vibration feature extraction implemented using an analysis and synthesis FIR filter bank. 
a means to focus on a subband of the original signal where the feature of interest is thought to lie, the net effect being a low-pass filtering or smoothing operation. The result is differentiated three times to produce the wavelet-based feature of interest. Figure 4.8 presents the wavelet feature extracted from the accelerometer signal shown in Figure 4.6, using the custom wavelet described above. The feature extracted is the spike shown in Figure 4.6b. The exact time of the event is precisely determined using this technique. Indeed, the event is modeled by imposing a pulse, whose magnitude is a function the of foreign object impact characteristics mentioned previously, on the fan disk. The two spikes shown in Figure 4.8 result from the rising and descending parts of that pulse "filtered" through the mechanical (i.e., rotor-bearing) system. The event input profile to the model (i.e., the pulse input described above) was considered to be appropriate for a significant, structurally damaging event i.e., where the foreign object absorbs virtually none of the energy of impact, resulting in complete and immediate transfer of energy to the fan disk. This would, for example, be the case for hard objects such as ice. For other scenarios, pulses of lower magnitude or with non-infinite rising (or descending) slopes may require higher-order differentiation for detection.

In summary, the result of the following sequence of operations:

- wavelet decomposition of a noisy ( e.g., bearing accelerometer) signal

- reconstruction of selected components (approximations or details at a selected scales) of the signal

- multiple differentiation of the reconstructed components

can precisely time-locate an abrupt, high-frequency, change in the signal. However, choice of too high a scale may result in the high-frequency event being filtered out of the signal. 
a)

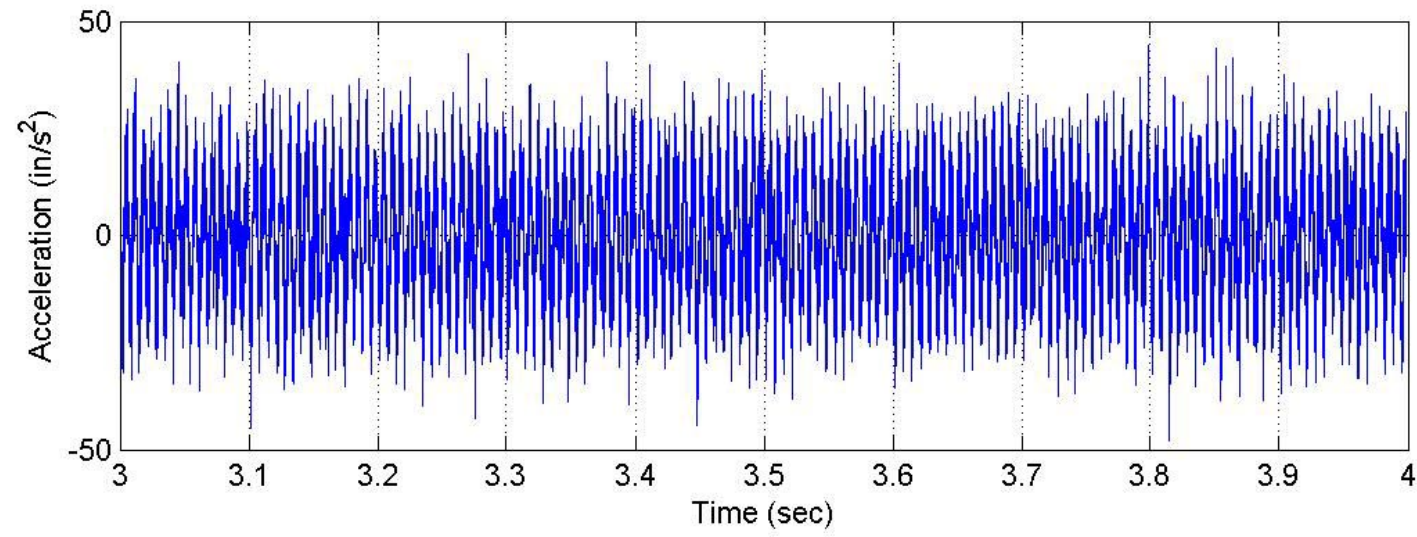

b)

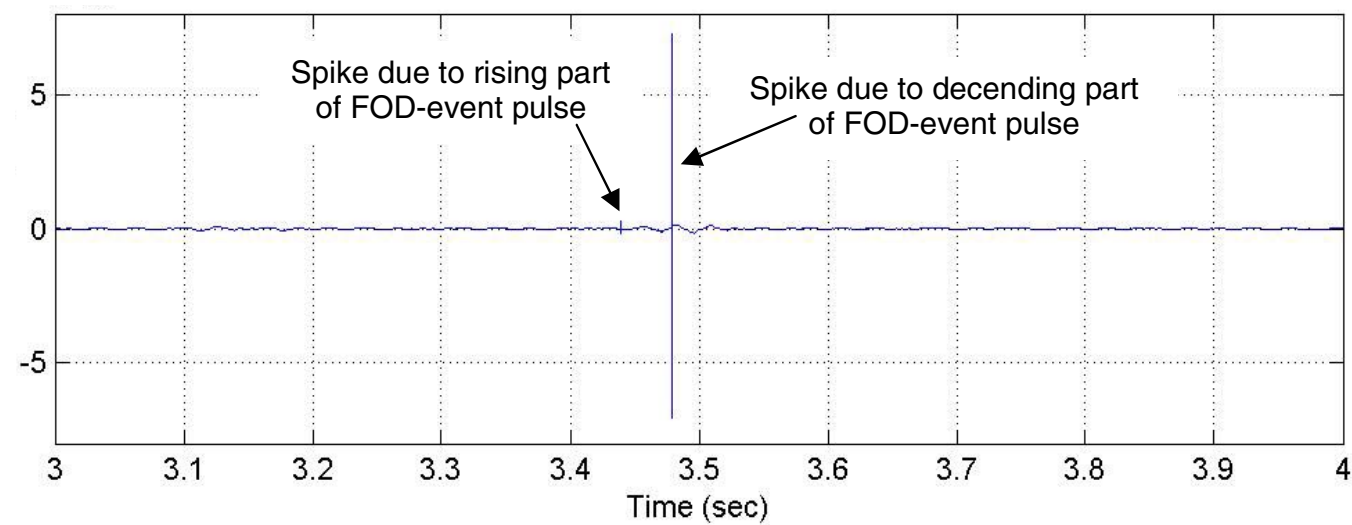

Figure 4.8. Wavelet feature extracted from noisy bearing accelerometer signal at location 40. a) accelerometer signal. b) Corresponding conditioned Daubechies 8 wavelet inverse transform, scale 8 approximation.

\subsection{Conclusion}

This paper describes the development of a wavelet-based feature (WF) specifically designed to identify the occurrence of FOD-events in gas turbine engines. The WF is extracted from rotor bearing accelerometer signals and is shown to be robust in the presence of significant noise. The technique is intended ultimately be combined with analytical measurements (e.g., Kalman filter thermal/health parameter estimates) for FOD-event detection via information fusion from these (and perhaps other) sources. It is envisioned that fusion of structural and thermal performance information will provide a pilot, or an autonomous vehicle, more confidence in a FOD-event diagnosis thus, enabling a corrective action to be based on a more informed decision. 
Due to the lack of high-frequency FOD-event test data in the open literature, a reduced-order turbofan structural model (ROM) was synthesized from a finite element model to support the investigation. The wavelet-based FOD-event detection scheme developed is "data driven" (i.e., not model-based), thus precise correspondence of the ROM to the FEM (which itself would probably not represent an actual engine with complete fidelity) is not essential. The ROM is considered to be "phenomenologically accurate," and shown to provide acceptable fidelity with regards to the application i.e., real-time diagnostic system development.

Using the state-space ROM, a sensor placement analysis was performed to determine the optimal accelerometer location for FOD-event detection. To demonstrate the robustness of the technique, testing was performed using the least optimal bearing location. For comparison, analysis of noise-free and noisy accelerometer signals was performed using a standard wavelet decomposition and shown to be inadequate for detecting FOD events. In the presence of significant noise ( $\mathrm{SNR}=3.5,11 \mathrm{~dB}$ ), precise location of the FOD event in time was obtained using the custom wavelet feature developed. Choice of the smoothing wavelet used (Daubechies 8) was subjective, and based on knowledge of the signal characteristic of interest i.e., a FOD event-induced abrupt change in an otherwise noisy signal.

Future work should include determining the optimal wavelet (and corresponding scale) to apply based on current information theoretic techniques such as maximum entropy. Additionally, combination of structural and thermal performance information could provide a robust diagnosis-of foreign object damage in specific engine components i.e., extending this research to the Fault Detection Isolation (FDI) problem. Continued development and verification of the feature presented would require high-frequency accelerometer data (i.e., sensor bandwidth greater than 10 $\mathrm{kHz}$ ) from FOD event engine tests at multiple operating conditions.

\subsection{Nomenclature}

$\mathrm{A}_{\mathrm{m}} \quad$ Reconstructed approximation component of wavelet-analyzed signal at scale $\mathrm{m}$

M Mass Matrix

C Damping Coefficient Matrix

$\mathrm{D}_{\mathrm{m}} \quad$ Reconstructed detail component of wavelet-analyzed signal at scale $\mathrm{m}$ 
DTWTD Discrete-time wavelet transform detail coefficient

DTWTA Discrete-time wavelet transform approximation coefficient

K Stiffness, Stiffness Matrix

G Gyroscopic Matrix

$\mathrm{C}_{\mathrm{xy}}, \mathrm{K}_{\mathrm{xy}} \quad$ Quantities with coupling between, e.g., the $\mathrm{x}$ and $\mathrm{y}$ degrees of freedom

$\alpha, \beta \quad$ Proportional damping coefficients

$\omega \quad$ angular frequency $(\mathrm{rad} / \mathrm{sec})$

$\mathrm{F}, \mathrm{f} \quad$ Frequency $(\mathrm{Hz})$

F $\quad$ Force

$\mathrm{I}_{\theta}, \mathrm{I}_{\alpha} \quad$ Moments of inertia about the $\mathrm{X}$ and $\mathrm{Y}$ axes respectively

$\mathrm{m} \quad$ Dyadic scale of wavelet-decomposed signal

$\mathrm{n} \quad$ Wavelet time delay in number of samples

$\eta(t) \quad$ Displacement in modal coordinates

$\mathrm{Y}(\mathrm{f}) \quad$ Discrete Fourier Transform of $\mathrm{y}(\mathrm{n})$

$\psi_{\mathrm{m}, \mathrm{n}} \quad$ Wavelet at scale $\mathrm{m}$ and translation $\mathrm{n}$

$\mathrm{q}(\mathrm{t}) \quad$ Displacement in physical coordinates

$\varphi_{\mathrm{m}, \mathrm{n}} \quad$ Wavelet scaling function at scale $\mathrm{m}$ and translation $\mathrm{n}$

\subsection{References}

[1] Society of Automotive Engineers, "Uncontained Turbine Engine Rotor Events Data Period 1984 Through 1989," SAE SP-1270, 1998.

[2] Mattingly, J.D., Heiser, W.H., Pratt, D.T., Aircraft Engine Design, Second Edition, American Institute of Aeronautics and Astronautics, Reston, VA, 2002. 
[3] Kerr L.J., Nemec T.S., Gallops, G.W., "Real-Time Estimation of Gas Turbine Engine Damage Using a Control Based Kalman Filter Algorithm”, ASME 91-GT-216, International Gas Turbine and Aeroengine Congress and Exposition, Orlando, FL, June 3-6, 1991.

[4] Luppold, R.H., Roman, J.R., Gallops, G.W., Kerr L.J., "Estimating In-Flight Performance Variations Using Kalman Filter Concepts”, AIAA-89-2584, AIAA 25th Joint Propulsion Conference, Monterey, CA, July 10-12, 1989.

[5] Klein, Lawrence A., Sensor and Data Fusion Concepts and Applications, 2nd Ed., SPIE Press Vol. TT35, 1999.

[6] Doebelin, Ernest O., Measurement Systems Application and Design, 5th Ed., McGraw Hill Publishing, New York, 2004.

[7] Lim, Meng Hee and M. Salman Leong, "Diagnosis for Loose Blades in Gas Turbines Using Wavelet Analysis," Proceedings of the ASME Turbo Expo 2003, Power for Land, Sea, and Air, June 16-19, 2003, Atlanta, Georgia.

[8] Juluri, Naresh and S. Swarnamani, "Improved Accuracy of Fault Diagnosis of Rotating Machinery Using Wavelet De-Noising and Feature Selection," Proceedings of the ASME Turbo Expo 2003, Power for Land, Sea, and Air, June 16-19, 2003, Atlanta, Georgia.

[9] Bay, John S, Fundamentals of Linear State Space Systems, McGraw Hill Publishing, New York, 2004, 1999.

[10] MATLAB Control System Toolbox Users Guide, The MathWorks Inc., Natick, MA, 1996.

[11] Ehrich, Fredric F., Handbook of Rotordynamics, Krieger Publishing Company, Inc., Malabar, Fl, 1999.

[12] Botman, M.,'Vibration Aspects of Small Turbine Engines in Aircraft Installations," Society of Automotive Engineers, 1980. 
[13] Gunter, E.J., DyRoBes Rotor Dynamic Analysis software training manual.

[14] Ogata, Katsuhiko, Modern Control Engineering, 2nd Ed., Prentice Hall Publishing, Englewood Cliffs, New Jersey, 1990.

[15] Lawrence, Charles, Kelly Carney and Vincente Gallardo, "Simulation of Aircraft Engine Blade-Out Structural Dynamics," NASA/TM-2001-210957/REV1, NASA-Glenn Research Center, Cleveland, $\mathrm{OH}$.

[16] Hatch, Micheal R, Vibration Simulation using MATLAB and ANSYS, Chapman and Hall / CRC Publishing, New York, 2000.

[17] Bishop, Robert H., The Mechatronics Handbook, CRC Publishing, New York, 2002.

[18] Chan, Y.T., Wavelet Basics, Kluwer Academic Publishers, Boston, MA, 1995.

[19] Newland, D.E., An Introduction to Random Vibrations, Spectral and Wavelet Analysis, Third Edition, John Wiley and Sons, Inc., New York, 1993.

[20] MATLAB Wavelet Toolbox Users Guide, The MathWorks Inc., Natick, MA, 2000 .

[21] Proakis, J.G., Rader, C.M., Ling, F., Nikias, C.L., Advanced Digital Signal Processing, Macmillan Publishing Co., New York, 1992.

[22] Mallat, S.G., “A Theory for Multiresolution Signal Decomposition: The Wavelet Representation," IEEE Transactions on Pattern Analysis and Machine Intelligence, Vol. 11, No. 7 , July 1989.

[23] Strang, G., "Wavelets and Dilation Equations: A Brief Introduction," Society for Industrial and Applied Mathematics Review, Vol. 31, No. 4, December 1989. 
[24] Soman, A.K., and P.P. Vaidyanathan, “ On Orthonormal Wavelets and Paraunitary Filter Banks,” IEEE Transactions on Signal Processing, Vol. 41, No. 3, March 1993.

[25] Mallat, S., Hwang, W.L., "Singularity Detection and Processing With Wavelets," IEEE Transactions on Information Theory, Vol. 38, No. 2, 1992. 
Public reporting burden for this collection of information is estimated to average 1 hour per response, including the time for reviewing instructions, searching existing data sources, gathering and maintaining the data needed, and completing and reviewing the collection of information. Send comments regarding this burden estimate or any other aspect of this collection of information, including suggestions for reducing this burden, to Washington Headquarters Services, Directorate for Information Operations and Reports, 1215 Jefferson Davis Highway, Suite 1204, Arlington, VA 22202-4302, and to the Office of Management and Budget, Paperwork Reduction Project (0704-0188), Washington, DC 20503.

\begin{tabular}{|l|l|l}
\hline 1. AGENCY USE ONLY (Leave blank) & $\begin{array}{c}\text { 2. REPORT DATE } \\
\text { August } 2004\end{array}$ & $\begin{array}{c}\text { 3. REPORT TYPE AND DATES COVERED } \\
\text { Technical Memorandum }\end{array}$ \\
\hline
\end{tabular}

4. TITLE AND SUBTITLE

5. FUNDING NUMBERS

Reduced-Order Modeling and Wavelet Analysis of Turbofan Engine

Structural Response Due to Foreign Object Damage (FOD) Events

6. AUTHOR(S)

WBS-22-303-30-72

James Turso, Charles Lawrence, and Jonathan Litt

1L161102AF20

\section{PERFORMING ORGANIZATION NAME(S) AND ADDRESS(ES)}

8. PERFORMING ORGANIZATION REPORT NUMBER

National Aeronautics and Space Administration

John H. Glenn Research Center at Lewis Field

Cleveland, Ohio 44135-3191

E-14612

\section{SPONSORING/MONITORING AGENCY NAME(S) AND ADDRESS(ES)}

National Aeronautics and Space Administration

Washington, DC 20546-0001

and

U.S. Army Research Laboratory

Adelphi, Maryland 20783-1145
10. SPONSORING/MONITORING AGENCY REPORT NUMBER

NASA TM-2004-213118

ARL-TR-3256

\section{SUPPLEMENTARY NOTES}

James Turso, QSS Group, Inc., Cleveland, Ohio 44135; Charles Lawrence, NASA Glenn Research Center; and Jonathan Litt, U.S. Army Research Laboratory, NASA Glenn Research Center. Responsible person, Jonathan Litt, organization code 5530, 216-433-3748.

\section{2a. DISTRIBUTION/AVAILABILITY STATEMENT}

12b. DISTRIBUTION CODE

Unclassified - Unlimited

Subject Categories: 39 and 07

Distribution: Nonstandard

Available electronically at http://gltrs.grc.nasa.gov

This publication is available from the NASA Center for AeroSpace Information, 301-621-0390.

13. ABSTRACT (Maximum 200 words)

The development of a wavelet-based feature extraction technique specifically targeting FOD-event induced vibration signal changes in gas turbine engines is described. The technique performs wavelet analysis of accelerometer signals from specified locations on the engine and is shown to be robust in the presence of significant process and sensor noise. It is envisioned that the technique will be combined with Kalman filter thermal/health parameter estimation for FOD-event detection via information fusion from these (and perhaps other) sources. Due to the lack of high-frequency FOD-event test data in the open literature, a reduced-order turbofan structural model (ROM) was synthesized from a finite element model modal analysis to support the investigation. In addition to providing test data for algorithm development, the ROM is used to determine the optimal sensor location for FOD-event detection. In the presence of significant noise, precise location of the FOD event in time was obtained using the developed wavelet-based feature.

\begin{tabular}{|c|c|c|}
\hline $\begin{array}{l}\text { 14. SUBJECT TERMS } \\
\text { Wavlet analysis; Dynami } \\
\text { Turbofan engine }\end{array}$ & tructural analysis; Foreign obj & damage; FOD; \\
\hline $\begin{array}{l}\text { 17. SECURITY CLASSIFICATION } \\
\text { OF REPORT } \\
\text { Unclassified }\end{array}$ & $\begin{array}{l}\text { 18. SECURITY CLASSIFICATION } \\
\text { OF THIS PAGE } \\
\text { Unclassified }\end{array}$ & $\begin{array}{l}\text { 19. SECURITY CLASSIFICATION } \\
\text { OF ABSTRACT } \\
\text { Unclassified }\end{array}$ \\
\hline
\end{tabular}

15. NUMBER OF PAGES

44

16. PRICE CODE

20. LIMITATION OF ABSTRACT

Standard Form 298 (Rev. 2-89)

Prescribed by ANSI Std. Z39-18 298-102 

